\title{
Patterns of tree growth in relation to environmental variability in the tropical dry deciduous forest at Mudumalai, southern India
}

\author{
Cheryl D Nath, H S Dattaraja, H S Suresh, N V Joshi and R Sukumar* \\ Centre for Ecological Sciences, Indian Institute of Science, Bangalore 560 012, India \\ *Corresponding author (Fax, 91-80-23602280; Email, rsuku@ces.iisc.ernet.in)
}

\begin{abstract}
Tree diameter growth is sensitive to environmental fluctuations and tropical dry forests experience high seasonal and inter-annual environmental variation. Tree growth rates in a large permanent plot at Mudumalai, southern India, were examined for the influences of rainfall and three intrinsic factors (size, species and growth form) during three 4-year intervals over the period $1988-2000$.

Most trees had lowest growth during the second interval when rainfall was lowest, and skewness and kurtosis of growth distributions were reduced during this interval. Tree diameter generally explained $<10 \%$ of growth variation and had less influence on growth than species identity or time interval. Intraspecific variation was high, yet species identity accounted for up to $16 \%$ of growth variation in the community. There were no consistent differences between canopy and understory tree growth rates; however, a few subgroups of species may potentially represent canopy and understory growth guilds. Environmentally-induced temporal variations in growth generally did not reduce the odds of subsequent survival.

Growth rates appear to be strongly influenced by species identity and environmental variability in the Mudumalai dry forest. Understanding and predicting vegetation dynamics in the dry tropics thus also requires information on temporal variability in local climate.
\end{abstract}

[Nath C D, Dattaraja H S, Suresh H S, Joshi N V and Sukumar R 2006 Patterns of tree growth in relation to environmental variability in the tropical dry deciduous forest at Mudumalai, southern India; J. Biosci. 31 651-669]

\section{Introduction}

Stem diameter is among the most sensitive character traits in trees likely to be affected by local environmental stresses (Dobbertin 2005). Dry tropical forests are excellent locations to study functional plasticity in tree diameter growth as they are characterized by large weather variations that include severe annual dry periods lasting from three to eight months (Murphy and Lugo 1986; Gerhardt and Hytteborn 1992). Here we examine tree diameter growth variations in relation to environmental, taxonomic and ontogenetic variations over 12 years in a tropical dry forest.

We have been studying the long-term dynamics of a tropical dry deciduous forest in Mudumalai, southern India, within a 50-hectare permanent forest plot (Sukumar et al 1992, 2004) that is part of an international network of large-scale and long-term Forest Dynamics Plots (Losos and Leigh 2004). Several features of the Mudumalai dry forest environment differ from those of other paleotropical or neotropical forests in the network. In particular, floristic diversity is relatively low (Losos and Leigh 2004), the canopy is relatively open and stochastic environmental fluctuations such as high intra and inter-annual rainfall variability, dry season ground fires and intensive browsing by large herbivores are common (Sukumar et al 1992, 2005). We would expect these environmental variations to be reflected in species' demographic traits, and the low floristic diversity to be associated with the way in which resources are partitioned in the community. Although tropical rainforests have been relatively well studied and characterized, similar studies on tropical dry forests are generally lacking (Murphy and Lugo 1986; Swaine et al 1990; Gerhardt and Hytteborn

Keywords. Diameter growth; environmental variability; growth strategy; rainfall; tropical dry forest 
1992). Thus, comparisons of the Mudumalai dry forest with wetter tropical forests are important for understanding the range of growth responses by tropical trees to environmental variation.

Previous studies using dendrometers to obtain daily, weekly or monthly measurements for up to two years in a range of forest types including dry lowland deciduous (Reich and Borchert 1984), moist semideciduous (Daubenmire 1972; Baker et al 2002, 2003a), and wet evergreen forests (Breitsprecher and Bethel 1990; Pelissier and Pascal 2000) have demonstrated that intra-annual or seasonal diameter variations are generally positively associated with rainfall and soil water. However, longer term studies (without dendrometers) have suggested that on an annual basis the relationship between rainfall and growth might become negative as the average annual rainfall increases. Thus, a four year study in a dry evergreen rainforest of Ghana (Swaine et al 1990; annual rainfall: $570-910 \mathrm{~mm}$, at least eight months with less than $100 \mathrm{~mm}$ ) found that faster growth occurred during higher rainfall years as expected based on seasonal patterns, whereas studies lasting up to eight years in moist forest sites of Panama (Condit et al 1993a, 2004; annual rainfall: $2030-2892 \mathrm{~mm}, 3.5$ to 4.5 months with less rainfall than potential evapotranspiration) found higher growth rates in saplings and several large trees during a drought year, and similarly a six-year study in a wet forest of Costa Rica (Clark and Clark 1992; annual rainfall: $3859 \mathrm{~mm}$, no months with less than $100 \mathrm{~mm}$ ) found highest median annual growth rates in the smallest and largest size classes during the lowest rainfall years and lowest growth during the highest rainfall years in most of the species studied. Similarly, a short twoyear dendrometer study in a wet evergreen forest of India (Pelissier and Pascal 2000; annual rainfall $>4000 \mathrm{~mm}$, five months with less than $100 \mathrm{~mm}$ ) also showed higher average annual growth during the relatively drier year. It has been hypothesized for moist forests that increased growth during relatively dry years may be due to reduced cloud cover resulting in increased photosynthetically active radiation (Clark and Clark 1992, 1994; Wright et al 1999; Condit et al 2004) or due to increased atmospheric temperatures during droughts (Condit et al 2004). In this context it is interesting to examine the long term relationship between rainfall and tree growth in the comparatively dry forest of Mudumalai.

With regard to intrinsic influences on tree growth, studies in tropical semi-deciduous and moist forests have reported that growth is strongly positively related to tree diameter (Swaine et al 1987; Condit et al 1993b; King et al 2006), that growth rates are species-specific (Lang and Knight 1983; Lieberman and Lieberman 1987; Clark and Clark 1992, 1999), and that different species may have specialized growth strategies relating to their demographic or functional guilds in the community (reviewed in Turner 2001). Although grouping species into separate guilds sometimes appears arbitrary (Turner 2001), growth-related continuums from the 'pioneer' strategy characterized by high growth and shade-intolerance, to the "mature canopy" or "understory shade-tolerant" strategy characterized by progressively lower growth rates (Lieberman et al 1985; Welden et al 1991; Condit et al 1996; Clark and Clark 1999; Nascimento et al 2005) have been described. These classifications in tropical moist forests generally have been associated with species' partitioning of the light gradient, either horizontally or vertically (Baker et al 2003b). It is not clear if similar evolutionary pressures have produced similar patterns of growth in relation to size and species identity in tropical dry forests, or if similar growth guilds can be identified here, as dry forests generally are open-canopied, species poor and floristically simple (Murphy and Lugo 1986; Gentry 1995).

In this study we examine the plasticity of Mudumalai dry forest tree diameter growth rates in relation to the external environmental factor of rainfall and the intrinsic factors of tree size, species identity and growth form. The following null hypotheses were tested:

(i) There is no significant variation in growth rates of trees during different census intervals.

(ii) Growth rates are not related to the extrinsic factor, rainfall.

(iii) Growth rates are not related to the intrinsic factors of stem diameter, species identity and growth form classification.

(iv) Growth rate variations across time intervals do not reduce survival.

\section{Methods}

\subsection{Study site}

During 1988-89 a 50-ha permanent vegetation monitoring plot was set up in the Mudumalai Wildlife Sanctuary (Tamilnadu, southern India), located between $11^{\circ} 35^{\prime} 41^{\prime \prime}$ and $11^{\circ} 35^{\prime} 57^{\prime \prime} \mathrm{N}$ latitudes, and $76^{\circ} 31^{\prime} 50^{\prime \prime}$ and $76^{\circ} 32^{\prime} 22^{\prime \prime}$ E longitudes (Sukumar et al 1992, 2004) to complement similar-sized plots established in the wetter tropical forest sites of Barro Colorado Island (BCI), Panama (Hubbell and Foster 1992) and Pasoh, Malaysia (Manokaran et al 2004). This paper presents analyses of data collected during the first twelve years of the plot, between 1988 and 2000. Vegetation in the plot is mainly tropical dry deciduous forest, and the average annual rainfall is approximately $1200-1250 \mathrm{~mm}$, received mainly between May and November. There is a pronounced 5-month dry season (less than $100 \mathrm{~mm}$ average rainfall per month), from around December to April. Extensive ground fires occurred in the plot during five of the twelve years: 1989, 1991, 1992, 1994 and 1996. Fairly abundant populations of large herbivores such as elephants 
(Elephas maximus), gaur (Bos gaurus), sambar deer (Cervus unicolor) and axis deer (Axis Axis), as well as smaller mammal species such as Hanuman langur (Semnopithecus entellus), wild pig (Sus scrofa), barking deer (Muntiacus muntjak), porcupine (Hystrix indica) and other rodents occur in the sanctuary and impact the vegetation by browsing, debarking, breaking or uprooting plants (Sukumar et al 2004).

\subsection{Data collection and growth rate calculations}

All woody species stems with a dbh of at least $10 \mathrm{~mm}$ (i.e., diameter at breast height, measured at $1.3 \mathrm{~m}$ or slightly higher if stem joints, buttresses or natural deformities occur at this height) were initially identified, tagged, mapped and measured in 1988-1989. Subsequently the plot has been enumerated annually to record deaths and recruits, while stem diameters or girths are measured every four years. This study used diameter or girth measurements from three 4-year intervals: 1988-1992, 1992-1996, and 1996-2000. Censuses were usually carried out during the wet season, between June and December, by which time most plants had flushed leaves and it was easier to differentiate dead from living stems.

The annual diameter growth per individual for each four-year interval was calculated as the following linear measure: $\left(D_{2}-D_{1}\right) / t$, where $D_{1}=$ diameter at the start of the interval, $D_{2}=$ diameter at the end of the interval and $t=$ time interval between the two measurement dates, in terms of years. Individuals with injuries or joints at the point of measure (between $1 \%$ and $4 \%$ of stems that survived each census) were excluded. Positive growth increments up to $75 \mathrm{~mm} . \mathrm{yr}^{-1}$ and negative diameter changes up to $75 \%$ of starting diameter per census interval (i.e. allowing shrinkage up to $7 \%$ per year) were considered as acceptable values, and this cut-off range excluded a further $1 \%$ to $2 \%$ of stems, thus leaving between 13221 and 14964 valid growth rates per interval for analyses. As Mudumalai is a disturbed and dynamic dry forest, we considered it possible that net annual shrinkage might occur in otherwise healthy stems during intervals of prolonged drought; however, these growth limits are wider than some previously used cutoffs (Condit et al 1993a, 1993b; Sheil 1995). Hence analyses were repeated using a narrower cutoff range (Sheil 1995) in addition to the above, which excluded an additional $1 \%$ from the first and third intervals and 5\% from the second interval. Results were generally similar regardless of the growth range used, and only the relatively important variations obtained with conservative growth cutoffs are reported.

Twelve size classes were used for most analyses, with the following limits (mm): 10, 20, 50, 100, 200, 300, 400, $500,600,700,800,900$ and 1500 (in some cases fewer classes were used), with minimum sample size $(N)$ of five per class.

\subsection{Time intervals and rainfall}

Community level variations across time intervals were examined using $95 \%$ confidence intervals for median growth rates. Growth and diameter distributions were checked for skewness and kurtosis, with probability values obtained from $t$-statistics (Sokal and Rohlf 1998) and by bootstrapping with 1000 iterations. Species' variations across time intervals were examined with paired $t$-tests and Wilcoxon matched pairs signed ranks tests with $P$-values generated using 1,000 bootstrap iterations. The value of alpha (type I error) was set at 0.05 , and Bonferroni correction was applied for the number of groups tested.

Rainfall data were available from Kargudi (located three $\mathrm{km}$ south of the plot) for $90 \%$ of the days between March 1990 and December 2000, and from Gamehut (located four $\mathrm{km}$ west of the plot) on a semi-monthly basis between January 1998 and December 2000. Missing rainfall data for Kargudi were estimated from Gamehut data as these two datasets were significantly correlated (Pearson $r=0.74$, $P<0.001)$. Missing Kargudi data were filled in the following three ways, generating three slightly differing datasets for Kargudi: (i) 'annual', using a linear regression equation between all the overlapping data of Kargudi and Gamehut, (ii) 'seasonal', using a separate linear regression equation for each of four seasons and (iii) 'monthly', using a linear or non-linear predictive equation for each of the twelve

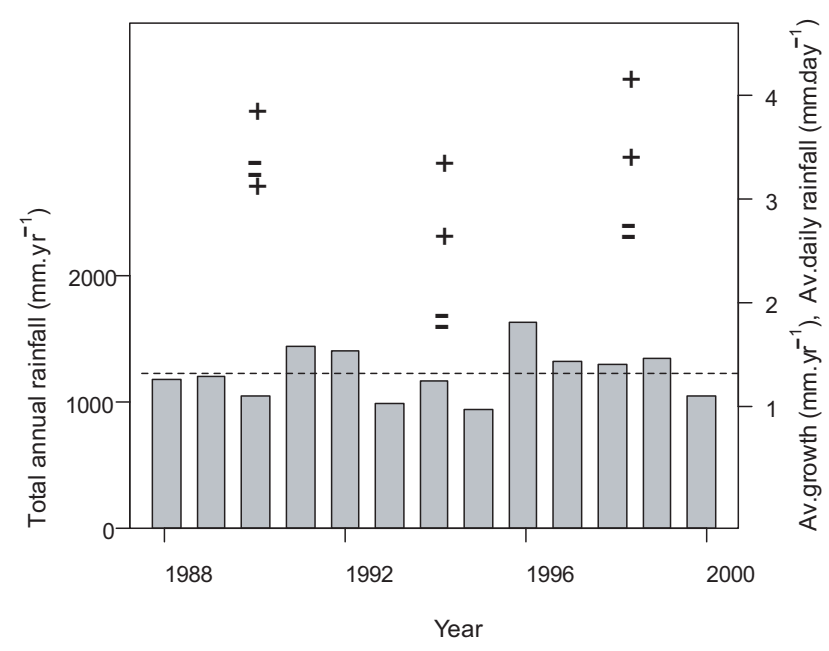

Figure 1. Bar chart of total annual rainfall $\left(\mathrm{mm} . \mathrm{yr}^{-1}\right)$ between 1988 and 2000 in the Mudumalai dry deciduous forest, averaged from Kargudi and Gamehut datasets. Mean annual rainfall, 1237 $\mathrm{mm} . \mathrm{yr}^{-1}$, is indicated by a dashed line [median rainfall (not shown) $=1207 \mathrm{~mm} \cdot \mathrm{yr}^{-1}$ ]. Plotted above the bars are the upper and lower 95\% confidence intervals of average annual growth ["Av.growth $\left(\mathrm{mm}_{\mathrm{yr}} \mathrm{yr}^{-1}\right)^{\text {"] }}$ of the three growth intervals (1988-1992, 1992-1996, 1996-2000), indicated by “-”, and the corresponding confidence intervals of average daily rainfall ["Av.daily rainfall $\left(\mathrm{mm}^{\mathrm{day}}{ }^{-1}\right)$ "] indicated by "+". 
months (see Appendix 1 for details). Annual rainfall values averaged across the four datasets (i.e. three Kargudi and one Gamehut dataset) are shown in figure 1. Average daily rainfall was calculated at the community level by using mean dates of consecutive censuses to delineate average census intervals, and at the individual level by using exact dates of girth measurement to delineate the rainfall interval per individual.

Consistency of the growth-rainfall relationship was examined using a sign test across pairs of intervals for species in different size classes (hereafter "species-size groups"). First, a measure of homogeneity was obtained between growth and rainfall changes across each pair of intervals for all species-size groups. For this, the sign of association (positive or negative) between the mean or median difference in growth and the corresponding mean or median difference in rainfall, per interval pair, was obtained for each species-size group. Consistency of these growthrainfall associations across different sets of interval pairs was then checked for by comparing each interval pair with another to obtain the proportion of groups with matching signs in both pairs of intervals. This gave a simple estimate of predictability of the growth-rainfall relationship for species in different size classes.

\subsection{Intrinsic factors}

The influence of stem diameter on growth rates of common species was examined using linear regressions to predict growth from the diameter, the natural $\log (\ln )$ of diameter or the squared radius. Interspecific variations were tested with single factor ANOVA per interval. Maximum potential growth rate per species was the average of the fastest growing $5 \%$ of stems.

All species were classified a priori, on the basis of field estimations of maximum height at maturity, into three growth form categories: canopy, understory and shrub (see Appendix 2). Principal components analysis (PCA, similarity matrix standardized with correlation) and cluster analyses (growth values converted to $z$-scores) were carried out using four growth parameters for juveniles (juveniles were trees $<100 \mathrm{~mm} \mathrm{dbh}$, except for Helicteres isora, the only shrub species used, $<40 \mathrm{~mm} \mathrm{dbh}$ ) and adults (nonjuveniles) per interval, to try and obtain growth form-related groups or a continuum. The following four parameters were used: average growth, high and low growth (highest and lowest $25 \%$ of growth rates, respectively) and relative growth (average growth rate divided by starting diameter). Seven to 12 species per interval could be tested for juveniles (minimum $N=20$ ) and 23 to 24 species per interval could be tested for adults (minimum $N=30$ ). Cluster analyses also were carried out on PCA scores, using Euclidean or Manhattan distances and single linkage, complete linkage,
Ward's and unweighted centroid algorithms (Ludwig and Reynolds 1988).

PCA and cluster analysis were carried out again after including deterministically calculated lifetime growth information (cf. Lieberman et al 1985). For this analysis data from all three intervals were used together for 16 species (with at least 150 individuals across the three intervals), to obtain seven parameters: the above four growth parameters, plus the additional variables of maximum dbh, average number of years to achieve maximum dbh, and minimum number of years to achieve maximum dbh. The average and minimum number of years to achieve maximum dbh were obtained from species' expected lifetime growth trajectories that were created using the average and maximum growth values per size class (size classes ranged from 10 to 80 $\mathrm{mm}$ per species), respectively. For size classes without individuals, a cubic spline was applied to estimate growth rates.

\subsection{Individual and interactive effects}

In order to assess the relative importance of different factors on growth and to highlight any important interactions between them, 2- and 3-way ANOVAs were carried out using the factors: species, growth form, time interval and dbh size class. Minimum sample size for unbalanced factorial models was 100 individuals per species or growth form per interval, and allowed individuals to be repeated across intervals. Balanced models with individuals selected randomly without replacement (to ensure independence within and across groups) also were run, with sample sizes of 20 or 30 per group for 2-way models and five per group for 3-way models. Balanced models were run 1000 times each and results are reported as proportions of iterations in which each factor or interaction term was significant at $P<0.05$.

\subsection{Growth variations and survival}

For all trees that survived the first two intervals, differences in relative growth rates of third interval survivors versus non-survivors were tested with $t$-tests and Wilcoxon signed ranks tests. Minimum sample size for survivors and nonsurvivors was five, and seven size classes were used (class limits: 10, 50, 100, 200, 300, 400, 600, and $1500 \mathrm{~mm}$ ). Growth distributions were trimmed by $5 \%$ of the range to eliminate outliers. Logistic regression analysis also was carried out to assess the effect of the difference in relative growth rates (trimmed by $5 \%$ of the range) between the first and second intervals on survival from natural causes other than fire and elephants, during each year between 1997 and 2000. All analyses were carried out using R, version 2.2.1. 


\section{Results}

\subsection{Variations across time intervals in relation to rainfall}

Average growth rates of all stems together during the three consecutive time intervals were $3.32 \pm 3.36 \mathrm{~mm}$. $\mathrm{yr}^{-1}$ (i.e. \pm SD), $1.84 \pm 3.03 \mathrm{~mm} . \mathrm{yr}^{-1}$ and $2.71 \pm 3.11 \mathrm{~mm} . \mathrm{yr}^{-1}$, respectively, with $95 \%$ confidence intervals $(\mathrm{CI})$ of \pm 0.05 $\mathrm{mm} . \mathrm{yr}^{-1}$ in all cases (figure 1). Growth rates were significantly different for all pairs of intervals. The corresponding average daily rainfall values experienced by individuals in the plot, averaged across the four datasets (i.e. three Kargudi datasets

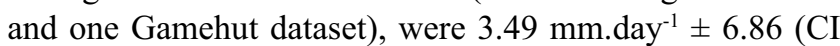
$=0.36), 3.0 \mathrm{~mm}$. day $^{-1} \pm 6.70(\mathrm{CI}=0.35)$ and $3.79 \mathrm{~mm}$. day $^{-1}$ $\pm 7.38(\mathrm{CI}=0.37)$, respectively. The overall pattern of high versus low rainfall across three intervals appears similar to the corresponding pattern in growth rates (figure 1).

At the community level all size classes, except the smallest size class, had highest growth in the first interval and lowest growth in the second interval (table 1, figure $2)$. Median growth in the second interval was significantly different $(P<0.05)$ from that of the first and third intervals in eleven and nine size classes, respectively, while growth rates of the first and third intervals were significantly different from each other in eight classes. There also was significant positive skewness and kurtosis of growth rates $(P<0.05$ with Bonferroni correction for number of size classes tested) in many small and medium size classes and in some large size classes during all intervals, which generally declined in value during the second interval, probably due to increased proportions of low and negative growth rates during this interval (table 1). Conservative growth cutoffs increased skewness of growth distributions as most size classes were significantly skewed, which did not generally reduce in the second interval as a result of excluding many negative values. Diameter distributions were rarely significantly skewed and were generally negatively kurtotic (table 1) indicating that growth rate skewness and kurtosis were not influenced by diameter distributions.

Over half of the species tested individually, including the four most dominant canopy species (Lagerstroemia microcarpa, Terminalia crenulata, Anogeissus latifolia and Tectona grandis), had significantly lower growth during the second interval compared to the first or third intervals in at least $50 \%$ of their size classes $(P<0.05$ with Bonferroni correction for number of size classes tested per species). Approximately $73 \%$ of species had significantly lower growth during the second interval in at least one size class, which collectively accounted for over half of all individuals tested. No species in any size class had significantly higher growth during the second interval except for 10-20 $\mathrm{mm}$ dbh stems of Cassia fistula, a common understorey tree, which grew faster in the second interval compared to the first.
The direction of association between growth and rainfall differences across interval pair 1-2 (1988-92 and 1992-96) was the same as that across interval pair 2-3 (1992-96 and 1996-2000) in $85 \%$ to $90 \%$ of 105 species-size groups tested (using mean or median growth and rainfall, with four different rainfall datasets), indicating a possible strong positive relationship between rainfall and growth for different species and size classes. However, evidence for this relationship was not so strong when the interval pair 1-3 (1988-92 and 1996-2000) was used. In this case fewer groups had matching growth-rainfall relationships with interval pair $1-2$ (31\% to $35 \%$ of 103 groups tested) or with interval pair $2-3$ ( $40 \%$ to $43 \%$ of 103 groups tested).

\subsection{Variations with size}

There was high variation in average growth across size classes per interval (table 1). Within size classes also there was large variation in growth, with standard deviations generally close to or greater than $100 \%$ of the means. During the first and third time intervals, growth rates generally increased with stem size; however, during the second interval the pattern was substantially different, with growth rates decreasing as tree size increased (figure 2). Among the common species this negative effect was most pronounced in very large stems of the canopy species $T$. crenulata and $T$. grandis, and to a lesser extent in the understory species Phyllanthus emblica. A window of generally high growth also was observed in the smallest stems $(10-20 \mathrm{~mm} \mathrm{dbh})$ and of low growth in medium-sized stems (approximately 50-300 $\mathrm{mm} \mathrm{dbh}$ ), respectively (figure 2).

In most of the common species dbh was not a significant predictor of growth. Linear regressions of growth on dbh for 17 to 20 common species (i.e. species with at least 50 valid growth rates per interval) showed that only five to eight species had significant regression slopes per interval $(P<0.05$, with Bonferroni correction for number of species tested), the magnitudes of which were low and explained $1 \%$ to $18 \%$ of growth variation. When using conservative growth cutoffs nine to ten species had significant slopes explaining less than $1 \%$ to $20 \%$ of the variation, although with both cutoffs most regressions explained $<10 \%$ of variation. Significant negative regression slopes occurred in two intervals for C. fistula and Helicteres isora, and the number of species with significant negative slopes increased in the second interval. In the four most abundant canopy species dbh explained only $1 \%$ to $7 \%$ of growth variation.

The predictive value of stem diameter improved only marginally or declined when using $\ln (\mathrm{dbh})$ or squared radius (to represent cross-sectional area per stem). The only exception was the understory species, Cordia wallichii, in which $\ln (\mathrm{dbh})$ predicted $32 \%$ of growth rate variation in the third interval. Thus, for most of the common species growth 
Table 1. Average growth, percent low growth, and significant skewness and kurtosis of growth rate distributions and dbh distributions in different size classes per interval.

\begin{tabular}{|c|c|c|c|c|c|c|c|}
\hline \multirow[b]{2}{*}{ Size class $(\mathrm{mm})$} & \multirow[b]{2}{*}{$N$} & \multirow[b]{2}{*}{ Av. growth $\pm \mathrm{SD}\left(\mathrm{mm} \cdot \mathrm{yr}^{-1}\right)$} & \multirow[b]{2}{*}{ Low growth $(\%)$} & \multicolumn{2}{|c|}{ Growth } & \multicolumn{2}{|c|}{ Dbh } \\
\hline & & & & Skewness & Kurtosis & Skewness & Kurtosis \\
\hline \multicolumn{8}{|l|}{$1998-1992$} \\
\hline $10-20$ & 485 & $3.19 \pm 3.07$ & 27 & 1.25 & 2.32 & {$[0.17]$} & -1.95 \\
\hline $20-50$ & 730 & $3.87 \pm 3.41$ & 19 & 0.99 & [3.08] & {$[0.17]$} & -1.28 \\
\hline $50-100$ & 1436 & $3.95 \pm 3.82$ & 22 & 1.86 & 8.14 & {$[-0.19]$} & -1.16 \\
\hline $100-200$ & 4396 & $2.67 \pm 2.98$ & 28 & 2.70 & 17.40 & {$[-0.03]$} & -1.15 \\
\hline $200-300$ & 3560 & $3.13 \pm 3.18$ & 21 & 2.51 & 19.34 & 0.22 & -1.12 \\
\hline $300-400$ & 1978 & $3.54 \pm 3.16$ & 16 & 2.04 & 10.28 & {$[0.17]$} & -1.17 \\
\hline $400-500$ & 1243 & $3.80 \pm 3.40$ & 15 & {$[0.73]$} & 7.77 & {$[0.15]$} & -1.08 \\
\hline $500-600$ & 662 & $3.99 \pm 4.01$ & 16 & {$[0.69]$} & 18.47 & {$[0.24]$} & -1.10 \\
\hline $600-700$ & 289 & $4.59 \pm 3.78$ & 12 & 1.24 & 4.19 & {$[0.22]$} & -1.10 \\
\hline $700-800$ & 109 & $4.88 \pm 4.70$ & 8 & 2.22 & 6.46 & {$[0.23]$} & {$[-0.72]$} \\
\hline $800-900$ & 42 & $5.21 \pm 4.34$ & 10 & 1.29 & {$[1.54]$} & {$[0.40]$} & {$[-1.15]$} \\
\hline $900-1500$ & 34 & $8.39 \pm 8.29$ & 6 & 1.71 & [2.37] & {$[1.03]$} & {$[0.61]$} \\
\hline \multicolumn{8}{|l|}{$1992-1996$} \\
\hline $10-20$ & 186 & $4.61 \pm 3.33$ & 16 & {$[0.26]$} & -0.94 & {$[-0.03]$} & {$[-1.06]$} \\
\hline $20-50$ & 433 & $3.19 \pm 3.11$ & 25 & 0.83 & [1.08] & {$[0.03]$} & -1.14 \\
\hline $50-100$ & 819 & $2.36 \pm 2.80$ & 36 & 0.86 & 1.75 & {$[-0.23]$} & -1.19 \\
\hline $100-200$ & 3914 & $1.51 \pm 2.50$ & 45 & 1.36 & 8.96 & {$[-0.08]$} & -1.13 \\
\hline $200-300$ & 3448 & $1.91 \pm 2.81$ & 38 & 0.72 & 3.84 & 0.17 & -1.12 \\
\hline $300-400$ & 2050 & $2.04 \pm 3.18$ & 38 & 0.95 & 6.21 & {$[0.15]$} & -1.15 \\
\hline $400-500$ & 1297 & $1.76 \pm 3.39$ & 42 & 0.87 & 5.59 & {$[0.10]$} & -1.17 \\
\hline $500-600$ & 692 & $1.48 \pm 3.86$ & 46 & [5.13] & 75.31 & {$[0.20]$} & -1.09 \\
\hline $600-700$ & 334 & $1.29 \pm 3.56$ & 46 & {$[0.03]$} & 3.17 & {$[0.16]$} & -1.14 \\
\hline $700-800$ & 131 & $0.71 \pm 3.68$ & 52 & {$[0.09]$} & 2.07 & {$[0.05]$} & {$[-1.25]$} \\
\hline $800-900$ & 46 & $0.17 \pm 4.63$ & 52 & {$[-1.56]$} & 6.42 & {$[0.54]$} & {$[-0.77]$} \\
\hline $900-1500$ & 39 & $0.35 \pm 7.18$ & 59 & {$[0.68]$} & {$[2.02]$} & [0.69] & {$[-0.77]$} \\
\hline \multicolumn{8}{|l|}{$1996-2000$} \\
\hline $10-20$ & 206 & $4.33 \pm 3.24$ & 17 & 0.69 & {$[0.34]$} & {$[-0.08]$} & {$[-0.59]$} \\
\hline $20-50$ & 504 & $3.64 \pm 3.28$ & 23 & 0.81 & {$[0.40]$} & {$[0.25]$} & -1.10 \\
\hline $50-100$ & 714 & $2.88 \pm 2.99$ & 29 & 2.40 & 11.73 & {$[-0.19]$} & -1.27 \\
\hline $100-200$ & 3558 & $1.95 \pm 2.64$ & 40 & 7.02 & 126.8 & -0.14 & -1.11 \\
\hline $200-300$ & 3394 & $2.56 \pm 2.55$ & 27 & 1.78 & 12.99 & {$[0.12]$} & -1.14 \\
\hline $300-400$ & 2184 & $3.09 \pm 3.71$ & 25 & 6.14 & 78.23 & {$[0.13]$} & -1.17 \\
\hline $400-500$ & 1328 & $3.19 \pm 3.48$ & 24 & 3.99 & 54.52 & [0.11] & -1.17 \\
\hline $500-600$ & 750 & $3.22 \pm 3.36$ & 21 & {$[1.52]$} & 18.77 & {$[0.16]$} & -1.16 \\
\hline $600-700$ & 357 & $3.57 \pm 3.42$ & 17 & 3.07 & 19.64 & {$[0.07]$} & -1.25 \\
\hline $700-800$ & 136 & $3.30 \pm 3.48$ & 23 & [1.13] & 4.38 & {$[-0.11]$} & {$[-1.10]$} \\
\hline $800-900$ & 49 & $3.54 \pm 4.89$ & 22 & [4.03] & [22.37] & {$[0.51]$} & {$[-0.67]$} \\
\hline $900-1500$ & 41 & $4.73 \pm 4.44$ & 20 & {$[0.74]$} & {$[0.36]$} & {$[1.00]$} & {$[0.58]$} \\
\hline
\end{tabular}

Skewness and kurtosis statistics were considered significant if the $P$-value obtained by $t$-statistics method and by bootstrap method (1000 iterations) were both $<0.05$ (with Bonferroni correction for number of size classes per interval). Non-significant skewness and kurtosis values are in square brackets. $\mathrm{N}$, total number of stems; Av.growth $\pm \mathrm{SD}$, average annual growth rate \pm standard deviation; Low Growth \%, percent of stems with less than 1 mm growth per year. 


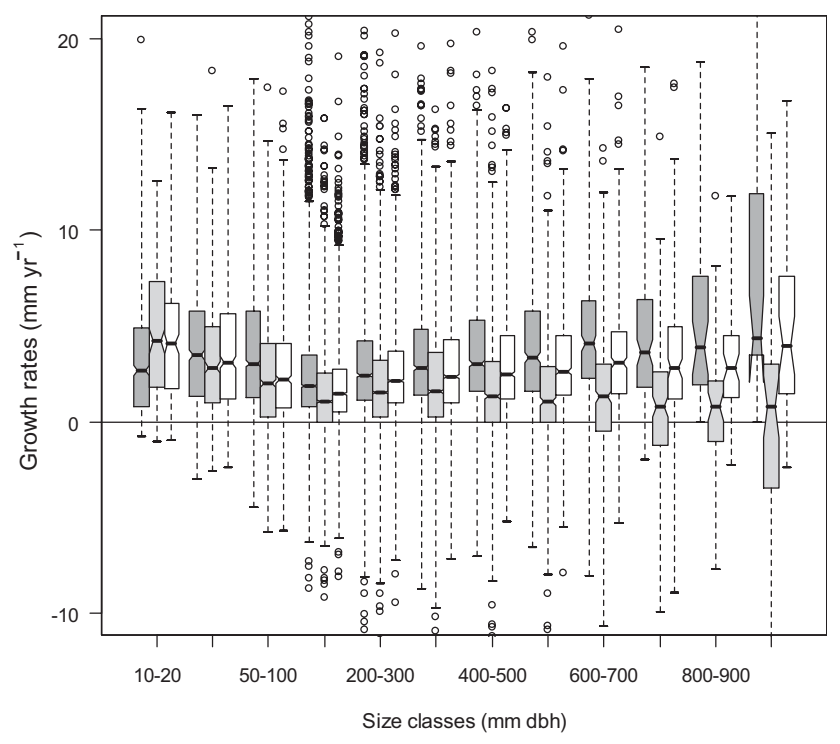

Figure 2. Boxplots of growth rate distributions in twelve size class during three time intervals. Whiskers are indicated with dotted lines, with a range of thrice the interquartile range. Notches signify $95 \%$ confidence limits for medians. Dark grey boxes $=1988-1992$; light grey boxes $=1992-1996 ;$ White boxes $=1996-2000$.

rate variations were only weakly related to stem diameter and in some cases the direction of the relationship changed with time.

\subsection{Variations across species}

Growth rates were examined in three size categories per species: small (10-50 $\mathrm{mm} \mathrm{dbh}$, medium (50-500 mm $\mathrm{dbh}$ ), and large (at least $500 \mathrm{~mm} \mathrm{dbh}$ ). Average growth in these categories varied widely across species, the highest being $7.9 \mathrm{~mm}_{\mathrm{yr}} \mathrm{r}^{-1}$ for medium stems of Hymenodictyon orixense in 1988-1992 and the lowest being -1.7 mm.yr 1 for large stems of Terminalia bellirica in 1992-1996 (table 2). Conservative growth cutoffs eliminated many negative growth rates especially from large stems during the second interval, and consequently the lowest average growth rate obtained was relatively higher, at $-0.3 \mathrm{~mm} . \mathrm{yr}^{-1}$, for medium stems of Schrebera swietenioides in 1992-1996. Standard deviations of species' growth rates per size class were generally high (usually larger than $50 \%$ of the means).

There was high variability in growth rates among species across time intervals. For example, T. bellirica in the large size category changed from being first-ranked in 1988-1992 with an average growth rate of $7.7 \mathrm{~mm} . \mathrm{yr}^{-1}$, to being lastranked in 1992-1996, with an average growth rate of -1.7 $\mathrm{mm} \cdot \mathrm{yr}^{-1}$ (table 2). On the other hand, Cordia obliqua in the small stems category and $C$. fistula in the medium size category showed relatively stable growth. A few species had generally high growth rates (for e.g. L. microcarpa, Kydia calycina, G. arborea, Grewia tiliaefolia and C. fistula), or generally low growth (for e.g. H. isora, T. crenulata, A. latifolia and Terminalia chebula).

Despite the generally high intraspecific growth variation, single-factor ANOVA of species' growth rates per interval was significant $(P<0.0001)$ with species identity explaining $15 \%$ to $16 \%$ of growth variation in the community $(16 \%$ to $20 \%$ when using conservative growth rate cutoffs). Tukey's HSD tests (for species with at least 50 valid growth rates) revealed that $56 \%$ to $68 \%$ of species pairs had significantly different growth rates per interval.

\subsection{Growth forms and growth strategy groupings}

Principal components analysis of species using four growthrelated parameters failed to consistently separate species on the basis of growth form. There were no significant differences between canopy and understory species (inclusive or exclusive of the only shrub with sufficient sample size to be used, $H$. isora), except for adults along the second PCA axis during the first and third intervals (one-way ANOVA and Wilcoxon signed ranks tests, $P<0.05$ with Bonferroni correction for three interval pairs tested). PCA biplots of juveniles and adults also showed no consistent groupings, nor any continuum of growth, that was associated with growth form. However, species scores of adults along the first axis were significantly correlated across interval pairs $1-3$ and $2-3$, while second axis scores were significantly correlated across the interval pair 1-3 (Pearson and Spearman correlations, $P<0.05$ with Bonferroni correction for number of interval pairs tested, figure 3). Use of conservative growth cutoffs produced significant correlations between species scores of all interval pairs, for both axes in the case of adults. For juveniles first axis scores were significantly correlated only across interval pair 2-3 (figure 3).

For adults the first axis scores were significantly negatively correlated with average, high and low growth in all three intervals, and also with relative growth in the second interval, while second axis scores were significantly positively correlated with relative growth in the first and third intervals (Pearson and Spearman correlations, $P<0.05$ with Bonferroni correction for number parameters tested). For juveniles the first axis scores similarly showed negative correlations for average, high and low growth in all three intervals, except for lack of significant correlation with low growth in the third interval, and second axis scores were significantly negatively correlated with relative growth in the first interval (Pearson and Spearman correlations, $P<0.05$ with Bonferroni correction for number parameters tested). Across intervals and size categories the first two 
Table 2. Growth rates per species in three size categories during three time intervals. Growth rates are ordered from highest to lowest mean growth rate in each size category per interval.

\begin{tabular}{|c|c|c|c|c|c|c|c|c|c|c|c|c|c|c|}
\hline \multicolumn{5}{|c|}{ 1988-1992 } & \multicolumn{5}{|c|}{ 1992-1996 } & \multicolumn{5}{|c|}{$1996-2000$} \\
\hline Sps & $N$ & Av. gr. & SD & Top 5\% & Sps & $\mathrm{N}$ & Av. Gr. & SD & Top 5\% & Sps & $\mathrm{N}$ & Av. Gr. & SD & Top 5\% \\
\hline \multicolumn{15}{|c|}{$10-50 \mathrm{~mm} \mathrm{dbh}$} \\
\hline allc & 9 & 5.29 & 4.29 & 13.63 & casf & 255 & 4.96 & 3.40 & 11.95 & corw & 12 & 5.82 & 5.66 & 14.76 \\
\hline lagl & 140 & 5.23 & 3.82 & 14.93 & lagl & 85 & 4.15 & 3.25 & 11.19 & casf & 432 & 4.45 & 3.22 & 11.65 \\
\hline coro & 23 & 4.30 & 2.80 & 9.66 & coro & 11 & 4.13 & 4.02 & 9.75 & coro & 11 & 3.96 & 4.05 & 10.09 \\
\hline casf & 454 & 4.24 & 3.62 & 11.98 & rand & 76 & 2.84 & 2.14 & 7.32 & lagl & 66 & 3.55 & 3.74 & 12.52 \\
\hline stet & 7 & 3.88 & 4.46 & 9.06 & step & 6 & 2.33 & 1.88 & 4.94 & allc & 5 & 2.91 & 2.41 & 5.50 \\
\hline corw & 11 & 3.86 & 1.75 & 6.46 & corw & 8 & 2.19 & 1.43 & 4.19 & rand & 56 & 2.71 & 2.37 & 7.94 \\
\hline dall & 10 & 3.83 & 3.76 & 11.79 & antd & 5 & 1.72 & 1.94 & 4.68 & heli & 94 & 2.32 & 2.32 & 7.62 \\
\hline antd & 7 & 3.39 & 2.05 & 5.74 & heli & 139 & 1.35 & 2.04 & 6.08 & tecg & 9 & 0.67 & 1.69 & 3.53 \\
\hline kydc & 31 & 3.37 & 2.78 & 8.73 & & & & & & & & & & \\
\hline elag & 8 & 3.16 & 2.19 & 7.13 & & & & & & & & & & \\
\hline rand & 92 & 3.16 & 1.97 & 7.39 & & & & & & & & & & \\
\hline indc & 9 & 2.50 & 2.23 & 5.99 & & & & & & & & & & \\
\hline malp & 9 & 2.50 & 1.54 & 4.65 & & & & & & & & & & \\
\hline heli & 317 & 2.46 & 2.55 & 8.67 & & & & & & & & & & \\
\hline writ & 9 & 2.41 & 2.49 & 7.53 & & & & & & & & & & \\
\hline step & 8 & 2.31 & 2.38 & 5.29 & & & & & & & & & & \\
\hline tecg & 35 & 1.56 & 1.82 & 5.85 & & & & & & & & & & \\
\hline shor & 7 & 1.40 & 1.26 & 3.24 & & & & & & & & & & \\
\hline \multicolumn{15}{|c|}{$50-500 \mathrm{~mm} \mathrm{dbh}$} \\
\hline hymo & 7 & 7.85 & 7.09 & 22.90 & ptem & 6 & 6.36 & 9.47 & 25.19 & syzc & 336 & 5.91 & 5.01 & 18.06 \\
\hline kydc & 634 & 6.39 & 4.66 & 18.80 & gmea & 12 & 4.87 & 9.16 & 21.40 & diom & 108 & 5.38 & 3.53 & 13.48 \\
\hline lanc & 6 & 6.37 & 3.41 & 11.77 & kydc & 186 & 3.69 & 3.41 & 11.68 & gret & 169 & 5.01 & 3.45 & 12.76 \\
\hline gmea & 17 & 5.24 & 4.29 & 12.94 & gret & 204 & 3.46 & 3.73 & 11.86 & gmea & 9 & 4.62 & 4.38 & 12.98 \\
\hline malp & 12 & 5.14 & 4.11 & 11.14 & scho & 19 & 3.45 & 5.53 & 16.37 & step & 67 & 4.07 & 4.76 & 19.02 \\
\hline terb & 8 & 4.99 & 6.44 & 20.38 & casf & 459 & 3.38 & 2.84 & 10.28 & dall & 25 & 3.98 & 4.03 & 13.02 \\
\hline bomm & 17 & 4.58 & 2.83 & 10.23 & diom & 105 & 3.24 & 3.27 & 10.62 & zizr & 8 & 3.91 & 1.75 & 7.58 \\
\hline gret & 254 & 4.57 & 3.40 & 13.18 & syzc & 319 & 3.17 & 3.00 & 10.40 & kydc & 80 & 3.72 & 3.66 & 13.32 \\
\hline lagl & 3229 & 4.40 & 3.62 & 14.49 & lagl & 3124 & 3.05 & 3.26 & 11.02 & lagl & 3050 & 3.54 & 3.19 & 12.15 \\
\hline coro & 32 & 4.38 & 3.34 & 10.47 & bomm & 14 & 2.92 & 2.95 & 8.66 & casf & 466 & 3.48 & 2.55 & 9.85 \\
\hline cand & 16 & 4.38 & 2.93 & 9.66 & allc & 6 & 2.56 & 2.12 & 5.76 & coro & 34 & 3.47 & 2.79 & 9.55 \\
\hline step & 72 & 4.22 & 2.72 & 10.78 & coro & 32 & 2.47 & 2.63 & 7.60 & scho & 15 & 3.13 & 2.15 & 6.78 \\
\hline scho & 21 & 4.10 & 3.70 & 12.41 & dall & 24 & 2.47 & 3.79 & 9.39 & terb & 6 & 3.11 & 3.26 & 7.46 \\
\hline syzc & 331 & 3.83 & 3.09 & 12.21 & corw & 38 & 2.13 & 3.90 & 10.99 & cand & 13 & 2.87 & 2.34 & 7.09 \\
\hline casf & 396 & 3.77 & 2.63 & 10.19 & lanc & 5 & 2.05 & 2.78 & 5.82 & case & 37 & 2.75 & 2.01 & 7.56 \\
\hline elag & 5 & 3.75 & 1.63 & 6.23 & step & 65 & 2.01 & 3.43 & 9.95 & rand & 386 & 2.73 & 3.08 & 10.42 \\
\hline butm & 29 & 3.69 & 3.01 & 11.17 & hymo & 7 & 1.97 & 3.22 & 7.32 & mitp & 11 & 2.61 & 2.34 & 5.87 \\
\hline diom & 108 & 3.68 & 2.68 & 9.45 & rand & 437 & 1.84 & 3.19 & 9.58 & ougo & 45 & 2.59 & 2.85 & 10.45 \\
\hline tecg & 1118 & 3.45 & 2.59 & 10.69 & baur & 7 & 1.84 & 2.96 & 7.33 & bomm & 14 & 2.58 & 1.97 & 6.81 \\
\hline
\end{tabular}


Table 2 (continued)

\begin{tabular}{|c|c|c|c|c|c|c|c|c|c|c|c|c|c|c|}
\hline mitp & 11 & 3.41 & 1.52 & 5.45 & case & 38 & 1.24 & 1.86 & 5.05 & hymo & 7 & 2.40 & 2.05 & 6.17 \\
\hline dall & 31 & 3.39 & 2.49 & 7.05 & tecg & 1051 & 1.24 & 2.14 & 5.88 & tecg & 1041 & 2.34 & 2.73 & 8.39 \\
\hline corw & 41 & 3.16 & 3.72 & 10.45 & mitp & 11 & 1.11 & 3.69 & 4.53 & baum & 20 & 2.23 & 1.96 & 6.07 \\
\hline ougo & 77 & 3.12 & 2.52 & 9.56 & anol & 2118 & 1.05 & 1.76 & 4.84 & brir & 16 & 2.22 & 2.24 & 6.57 \\
\hline zizr & 6 & 3.10 & 2.38 & 6.70 & ougo & 67 & 1.03 & 2.57 & 6.02 & corw & 40 & 2.00 & 2.49 & 7.82 \\
\hline flai & 7 & 3.06 & 1.39 & 5.23 & stet & 274 & 0.99 & 2.30 & 6.27 & phye & 367 & 1.98 & 3.78 & 10.66 \\
\hline stet & 288 & 2.90 & 2.52 & 9.91 & cand & 14 & 0.98 & 1.90 & 3.70 & cara & 17 & 1.97 & 1.31 & 4.26 \\
\hline ptem & 10 & 2.87 & 4.65 & 12.75 & phye & 414 & 0.89 & 2.03 & 6.57 & malp & 5 & 1.85 & 2.96 & 6.88 \\
\hline garp & 8 & 2.77 & 2.00 & 6.04 & cara & 19 & 0.77 & 3.29 & 7.57 & anol & 2107 & 1.77 & 2.19 & 6.37 \\
\hline sema & 11 & 2.64 & 2.51 & 7.03 & malp & 7 & 0.74 & 3.02 & 5.74 & heli & 21 & 1.76 & 2.61 & 6.90 \\
\hline zizx & 11 & 2.53 & 2.09 & 5.72 & zizx & 5 & 0.68 & 3.90 & 4.88 & stet & 264 & 1.68 & 2.07 & 7.58 \\
\hline brir & 23 & 2.51 & 2.84 & 10.23 & butm & 27 & 0.62 & 3.48 & 6.95 & eriq & 10 & 1.30 & 2.15 & 6.46 \\
\hline rand & 524 & 2.40 & 2.78 & 9.40 & tert & 2113 & 0.61 & 1.91 & 4.96 & lagp & 60 & 1.22 & 1.89 & 6.16 \\
\hline lagp & 68 & 2.32 & 2.21 & 9.09 & baum & 21 & 0.54 & 2.40 & 4.11 & tert & 2175 & 1.21 & 1.71 & 5.39 \\
\hline baum & 22 & 2.28 & 2.60 & 9.34 & brir & 20 & 0.44 & 2.50 & 4.91 & garp & 5 & 1.15 & 1.39 & 2.87 \\
\hline anol & 2156 & 2.27 & 2.25 & 8.09 & lagp & 65 & 0.26 & 2.00 & 3.20 & lanc & 5 & 1.14 & 1.15 & 2.83 \\
\hline case & 41 & 2.19 & 2.75 & 5.70 & terc & 39 & 0.18 & 1.02 & 1.89 & terc & 40 & 0.98 & 1.43 & 4.51 \\
\hline phye & 443 & 1.78 & 2.04 & 7.71 & garp & 6 & -0.21 & 1.58 & 1.56 & schs & 29 & 0.77 & 1.53 & 4.78 \\
\hline cara & 20 & 1.69 & 2.37 & 6.73 & sema & 9 & -0.25 & 3.10 & 3.86 & sema & 7 & 0.65 & 0.81 & 2.15 \\
\hline oled & 5 & 1.67 & 1.23 & 3.35 & heli & 41 & -0.25 & 1.75 & 3.57 & butm & 27 & 0.35 & 3.19 & 8.15 \\
\hline tert & 2184 & 1.54 & 2.19 & 7.61 & schs & 32 & -0.59 & 1.23 & 1.28 & baur & 6 & 0.01 & 3.50 & 2.82 \\
\hline schs & 41 & 1.51 & 1.58 & 5.69 & zizr & 7 & -0.82 & 4.45 & 4.96 & & & & & \\
\hline eriq & 123 & 1.42 & 2.65 & 8.16 & terb & 6 & -0.93 & 3.22 & 4.96 & & & & & \\
\hline baur & 7 & 1.40 & 0.62 & 2.52 & eriq & 27 & -1.47 & 2.52 & 1.80 & & & & & \\
\hline heli & 73 & 1.33 & 2.66 & 8.28 & & & & & & & & & & \\
\hline terc & 44 & 0.90 & 1.49 & 3.01 & & & & & & & & & & \\
\hline \multicolumn{15}{|c|}{$>500 \mathrm{~mm} \mathrm{dbh}$} \\
\hline terb & 25 & 7.70 & 8.29 & 25.84 & gret & 111 & 4.34 & 4.22 & 14.27 & syzc & 26 & 7.25 & 3.38 & 14.87 \\
\hline bomm & 18 & 7.41 & 7.12 & 24.95 & lag1 & 63 & 3.97 & 3.65 & 11.76 & gret & 121 & 7.06 & 4.70 & 18.68 \\
\hline lagl & 47 & 6.74 & 3.82 & 16.79 & syzc & 23 & 3.72 & 5.51 & 16.74 & gmea & 15 & 5.31 & 8.05 & 20.68 \\
\hline gmea & 19 & 6.34 & 6.79 & 20.64 & lanc & 7 & 3.35 & 3.66 & 10.99 & lagl & 93 & 4.88 & 3.21 & 11.04 \\
\hline gret & 86 & 5.46 & 5.12 & 16.07 & scho & 48 & 3.14 & 9.53 & 30.05 & garp & 13 & 4.35 & 4.10 & 9.99 \\
\hline ptem & 6 & 5.36 & 3.03 & 11.08 & garp & 14 & 2.16 & 4.28 & 8.82 & scho & 51 & 4.20 & 5.32 & 11.13 \\
\hline garp & 16 & 5.33 & 4.59 & 14.37 & gmea & 13 & 1.95 & 4.93 & 7.06 & bomm & 19 & 3.68 & 2.28 & 8.05 \\
\hline lanc & 6 & 5.32 & 3.33 & 10.47 & anol & 16 & 1.70 & 3.43 & 6.68 & lanc & 8 & 3.41 & 3.76 & 12.04 \\
\hline step & 20 & 5.00 & 2.73 & 10.45 & ptem & 7 & 1.42 & 3.81 & 8.26 & step & 22 & 3.13 & 1.71 & 7.02 \\
\hline tecg & 514 & 4.72 & 3.59 & 14.62 & tecg & 556 & 1.00 & 2.87 & 6.57 & ptem & 7 & 3.13 & 3.46 & 10.32 \\
\hline scho & 45 & 4.48 & 3.75 & 14.54 & step & 22 & 0.13 & 3.37 & 4.72 & tecg & 590 & 3.07 & 2.80 & 9.84 \\
\hline anol & 13 & 4.12 & 2.36 & 7.86 & tert & 295 & -0.20 & 2.31 & 4.28 & anol & 13 & 2.62 & 2.26 & 6.04 \\
\hline syzc & 21 & 3.73 & 9.12 & 16.63 & bomm & 19 & -0.22 & 5.46 & 4.60 & terb & 25 & 2.48 & 3.20 & 10.04 \\
\hline dall & 5 & 2.48 & 2.04 & 6.01 & terb & 26 & -1.71 & 5.60 & 8.37 & dall & 8 & 1.69 & 1.83 & 5.71 \\
\hline tert & 279 & 2.37 & 3.12 & 11.64 & & & & & & tert & 301 & 1.55 & 1.76 & 5.96 \\
\hline
\end{tabular}

Sps, species code (corresponding species' names are given in Appendix 2); $N$, sample size (minimum = 5); Av. gr., average annual growth rate; $\mathrm{SD}$, standard deviation; Top $5 \%$ - mean of highest $5 \%$ of growth rates (all growth measurements are in $\mathrm{mm}_{\mathrm{m}} \mathrm{yr}^{-1}$ ). 
Intervals 1 - 2 adults. $\mathrm{r}=0.34$, rho $=0.42$

Intervals $1-3$ adults $r=0.47$,rho=0. $6^{*}$

Intervals 2 - 3 adults.r=0.68*, rho $=0.72^{*}$
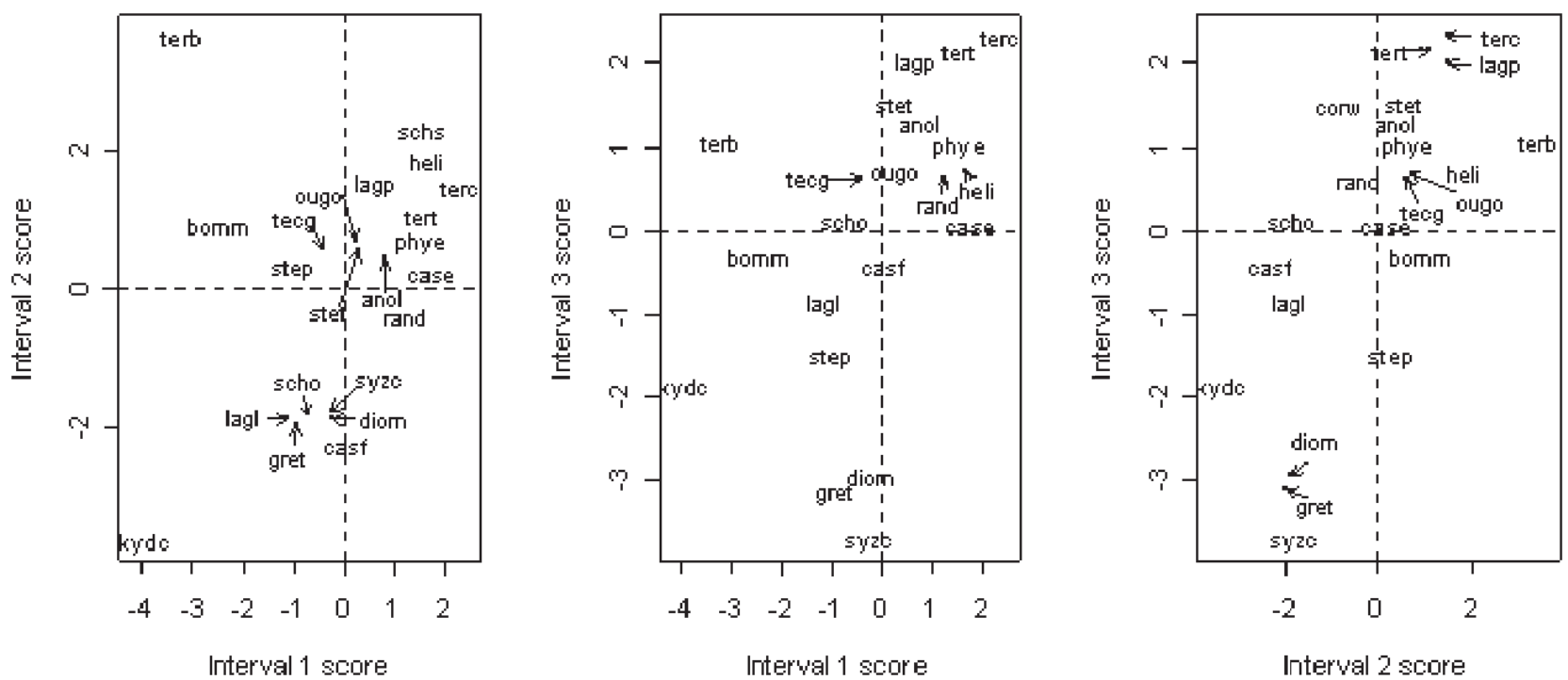

Interwals 1 - 2 juv. $r=0.55$, rho=0.4

Intervals $1-3$ juv. $r=0.89^{*}, r h o=0.75$
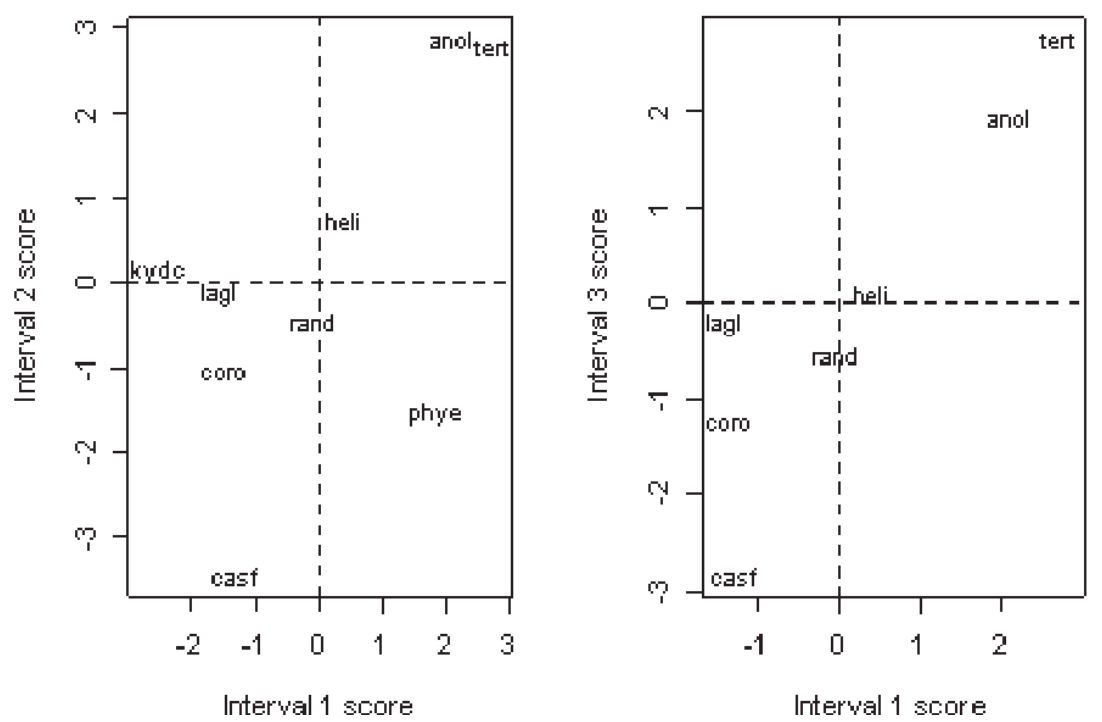

Intervals 2 - 3 juv $r=0.98^{*}$, rho $=0.96^{*}$

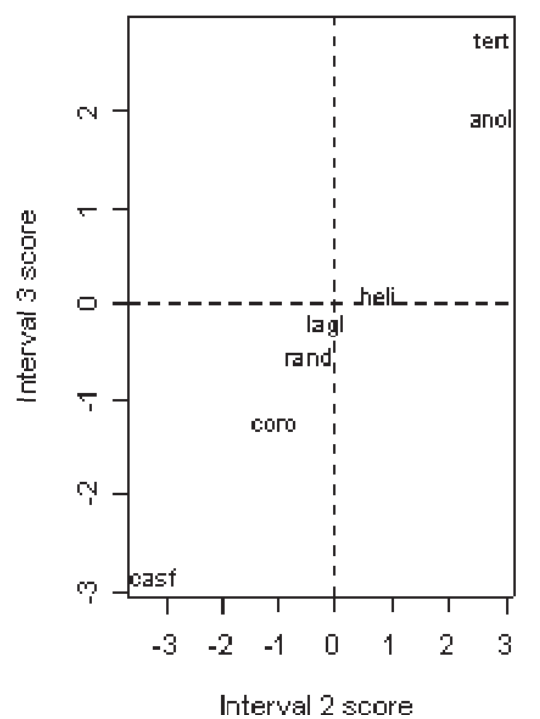

Figure 3. Correlation plots of PCA Axis 1 species scores across paired time intervals, using adults and juveniles of seven to 24 species. There was no clear separation of canopy and understorey trees. Species' scientific names associated with the four-letter codes are given in Appendix 2. juv., Juveniles; r, Pearson correlation coefficient; rho, Spearman rank correlation coefficient. Significant correlation coefficients $(P<0.05)$ are indicated by “*”.

components accounted for $89 \%$ to $96 \%$ of variation, with the first axis explaining $69 \%$ to $90 \%$ of variation and the second axis explaining $6 \%$ to $21 \%$ of variation.

A few species appeared to form smaller groupings independent of other species, such as $T$. crenulata and $A$. latifolia (both canopy species) juveniles, which occurred close together in PCA biplots on account of their significantly lower values for average, high and relative growth rates (one-way ANOVA, $P<0.05$ with Bonferroni correction for number of growth parameters tested, inconsistent across three intervals; non-significant with Wilcoxon signed ranks test). Among adults, a group of nine canopy species, $T$. bellirica, Bombax ceiba, S. oleosa, G. tiliaefolia, S. colais, T. grandis, L. microcarpa, Diospyros montana and $S$. cumini generally 
had relatively large values for average, high and low growth rates (one-way ANOVA and Wilcoxon signed ranks test, $P<0.05$ with Bonferroni correction for number of growth parameters tested). Interestingly, the understory species $K$. calycina and C. fistula also had large values for average, high and low growth rates, and strengthened the significant differences obtained when added to the canopy species group above. K. calycina and C. fistula adults occurred in proximity of each other during all three intervals due to their generally high relative growth rates, as also in the case of $H$. isora (one-way ANOVA and Wilcoxon signed ranks test, $P<0.05$ with Bonferroni correction for number of growth parameters tested, inconsistent across three intervals). Cluster analyses using the four growth-related parameters (non-standardized or standardized) or PCA scores together generally placed canopy species in the same clusters as understory species, showing that there was no overall difference between the growth rates of understory and canopy species (shrubs were represented by only one species, $H$. isora). The only species that consistently clustered together when using standardized growth parameters or PCA scores were $T$. crenulata and $A$. latifolia juveniles.

The addition of lifetime growth trajectory data also failed to produce clear growth form-based groupings. There were no significant differences between canopy and understory species (inclusive or exclusive of $H$. isora) when using broad growth rate cutoffs, but with conservative growth cutoffs there were significant differences of second axis species scores between the two growth form categories (oneway ANOVA and Wilcoxon signed ranks tests, $P<0.05$ ). The first two principal components explained $80 \%$ of variation. The first axis (explaining $47 \%$ of variation) was significantly negatively correlated with average, high and low growth rates and significantly positively correlated with the average number of years to attain maximum diameter, however, when using conservative growth rate cutoffs the average number of years to attain maximum diameter was not correlated with the first axis. The second axis was significantly negatively correlated with maximum dbh (Pearson and Spearman correlations, $P<0.05$ with Bonferroni correction for number parameters tested) when using wider cutoffs, and also with mean number and minimum number of years to maximum diameter, as well as correlated in the opposite direction with relative growth rates when using conservative growth cutoffs. Cluster analysis using the seven standardized parameters or all PCA scores together revealed a group of five canopy species, L. microcarpa, Diospyros montana, $G$. tiliaefolia, S. cumini and S. colais, that generally occurred together. Another generally consistent cluster was a mixed group of four canopy species, A. latifolia, Lagerstroemia parviflora, Radermachera xylocarpa and Desmodium oojeinense, along with two understory species, P. emblica and C. spinosa.

\subsection{Relative importance of individual and interactive effects on growth}

In unbalanced ANOVA models, all independent terms and two-way interaction terms were significant $(P<0.05)$, whereas three-way interactions were generally not significant when less than five size classes were used. In balanced models, among the individual factor effects species identity always had the highest proportions of iterations with significant effects on growth rates $(\geq 99 \%)$, while growth form usually showed the lowest proportion of significant iterations (generally $<50 \%$, table 3 ). Time interval often was significant in $\geq 90 \%$ of iterations, and generally showed higher proportions than dbh. The use of conservative growth cutoffs generally reduced proportions of significant iterations for the time intervals factor and slightly increased the proportions for growth forms and dbh classes. Despite this, time intervals were significant more often than dbh and growth form.

In balanced models the interaction terms generally were significant less often than independent factors. Twoway interactions usually were significant in $<30 \%$ of iterations, while three-way interactions between factors were significant in $<10 \%$ of iterations. Relatively common significant interactions occurred between species and time intervals, between growth form and dbh size classes, and between time intervals and large numbers of size classes (table 3).

These results suggest that among the factors tested species identity was most closely related to growth variations, and the next most important factor was time interval. Dbh size class was significant slightly less often, while growth form was least often significantly associated with growth variations.

\subsection{Growth rate variations and survival}

For the majority of species and size classes tested (totaling 50 groups) across four years of mortalities, relative growth during the first two intervals was not related to survivorship in the third interval. Only L. microcarpa sapling (100-200 mm dbh) survivors of 1998 and 2000 had significantly higher relative growth than non-survivors $(P<0.05$, with Bonferroni correction for species-size groups per year), when considering mortalities due to natural agents other than fire and elephants. However, $K$. calycina sapling survivors of elephant-caused mortality in the same size class in 1998 and in the 50-100 mm dbh size class in $1997 \mathrm{had}$ significantly lower relative growth than non-survivors.

Almost all of the 23 species-size groups showed no significant relationship between survival in the third interval and the difference in relative growth rates of the first two intervals. Only medium-sized saplings (100-200 mm dbh) 
Table 3. Proportions per 1000 iterations, of significant results (at $P<0.05$ ) per explanatory factor or interaction term in balanced factorial 2- and 3-way ANOVA models, using individual growth rates as the dependent factor.

\begin{tabular}{|c|c|c|c|c|c|c|c|c|c|c|c|}
\hline Model & $\mathrm{sp}$ & grf & int & dbh & sp*int & grf*int & $\mathrm{sp} * \mathrm{dbh}$ & grf*dbh & int*dbh & sp*int*dbh & grf*int*dbh \\
\hline \multicolumn{12}{|l|}{ 2-way ANOVA } \\
\hline 13 sp, 3 int, $N=30$ & 1.00 & & 1.00 & & 0.89 & & & & & & \\
\hline $16 \mathrm{sp}, 3$ int, $N=20$ & 1.00 & & 1.00 & & 0.70 & & & & & & \\
\hline 3 grf, 3 int, $N=30$ & & 0.67 & 0.78 & & & 0.06 & & & & & \\
\hline $2 \mathrm{grf}^{\#}, 3$ int, $N=30$ & & 0.31 & 0.71 & & & 0.06 & & & & & \\
\hline 3 grf, 3 int, $N=20$ & & 0.47 & 0.62 & & & 0.06 & & & & & \\
\hline $5 \mathrm{sp}, 5 \mathrm{dbh}, N=20$ & 1.00 & & & 0.82 & & & 0.26 & & & & \\
\hline $8 \mathrm{sp}, 3 \mathrm{dbh}, N=20$ & 1.00 & & & 0.52 & & & 0.27 & & & & \\
\hline 2 grf, $5 \mathrm{dbh}, N=30$ & & 0.08 & & 0.51 & & & & 0.41 & & & \\
\hline $2 \mathrm{grf}, 3 \mathrm{dbh}, N=30$ & & 0.08 & & 0.15 & & & & 0.44 & & & \\
\hline 2 grf, $2 \mathrm{dbh}, N=30$ & & 0.22 & & 0.42 & & & & 0.27 & & & \\
\hline 3 int, $7 \mathrm{dbh}, N=30$ & & & 1.00 & 0.80 & & & & & 0.61 & & \\
\hline 3 int, $5 \mathrm{dbh}, N=30$ & & & 0.97 & 0.65 & & & & & 0.20 & & \\
\hline 3 int, $3 \mathrm{dbh}, N=30$ & & & 0.90 & 0.16 & & & & & 0.16 & & \\
\hline \multicolumn{12}{|c|}{ 3-way ANOVA, $N=5$} \\
\hline $3 \mathrm{sps}, 3 \mathrm{int}, 5 \mathrm{dbh}$ & 1.00 & & 0.88 & 0.59 & 0.09 & & 0.27 & & 0.10 & 0.08 & \\
\hline $6 \mathrm{sps}, 3$ int, $3 \mathrm{dbh}$ & 1.00 & & 0.96 & 0.48 & 0.36 & & 0.25 & & 0.16 & 0.05 & \\
\hline $7 \mathrm{sps}, 3 \mathrm{int}, 2 \mathrm{dbh}$ & 0.99 & & 0.42 & 0.13 & 0.10 & & 0.37 & & 0.07 & 0.08 & \\
\hline 2 grf, 3 int, 5 dbh & & 0.07 & 0.51 & 0.27 & & 0.07 & & 0.24 & 0.07 & & 0.05 \\
\hline 2 grf, 3 int, 3 dbh & & 0.07 & 0.36 & 0.10 & & 0.05 & & 0.24 & 0.07 & & 0.03 \\
\hline 2 grf, 3 int, 2 dbh & & 0.16 & 0.15 & 0.22 & & 0.05 & & 0.17 & 0.05 & & 0.05 \\
\hline
\end{tabular}

"shrubs excluded

Factors used in the models are as follows: sp, species identity; grf, growth form identity; int, time intervals; dbh, diameter size categories. First and second order interaction terms per model are indicated with “*”. $N$, Sample size per group.

of L. microcarpa showed a significant negative relationship between the odds of survival in 1998 and relative growth rate difference of the preceding intervals $(P<0.05$, with Bonferroni correction for species-size groups per year).

\section{Discussion}

\subsection{Growth variations in relation to external environmen- tal factors}

Large variations in growth rates reflect the dynamic nature of species' growth during the period of the study, and indicate plasticity in growth responses of Mudumalai dry forest trees to their environment. Community and species growth rates appear to show high sensitivity to large-scale environmental variations across time, with a pronounced effect during the second interval (1992-1996). The widespread nature of relatively reduced growth in the second interval across the plot community indicates that one or more common environmental factors strongly influenced diameter growth rates during this period.
Extreme shrinkage in large trees was excluded from analyses by conservative growth cutoffs; however, previous studies with dendrometers have shown that large trees, especially those with few neighbours, may experience greater seasonal drought stress and consequently shrink more than smaller trees (Pelissier and Pascal 2000; Baker et al 2002). Also, for some large trees in this forest with fire-adapted thick and fissured bark, measurement error may be up to $5 \mathrm{~mm}$ over the four-year interval. Hence, a lower growth limit of $-2 \mathrm{~mm} . \mathrm{yr}^{-1}$ may not be appropriate for the Mudumalai dry forest. Interactions between time intervals and species or size classes suggests variations in the sensitivity of different species and size classes to different levels of environmental stress, which may promote species coexistence or reveal specific adaptations. Further study of these interactions is required.

Growth rates of most small and medium-sized stems were significantly positively skewed, and kurtotic suggesting that most trees in small and medium-size classes had highly similar growth rates, perhaps due to suppression by neighbours. Harper (1977) described such plant populations as being largely composed of "suppressed weaklings", 
implying that only a few individuals exhibited much greater than average growth while most individuals tended to cluster around low growth values, especially under density stress. Similar effects were found in a Costa Rican rain forest (Clark and Clark 1992), and in Sarawak, Malaysia (Primack et al 1985). Interestingly, in 1992-1996 skewness and kurtosis values were reduced, suggesting less competitive interactions under unfavourable growth conditions (although this effect was not obvious with conservative cutoffs).

Lower than average rainfall during the second time interval was associated with significantly lower growth in several size classes of common species in the plot. Although the growth-rainfall relationship was not predictable when comparing the first with the third interval, this is not surprising as the magnitude of change in growth across these two intervals was less than that between the second interval and either of these intervals and, in addition, the rainfall ranges of the first and third intervals overlapped more with each other than with that of the second interval. Confounding individual variations (for e.g. initial size of individuals) or environmental variations (such as elevated temperatures or differences in fire occurrences) also may have been greater between the first and third intervals due to the longer time gap than when either of these intervals was paired with the second.

The large rainfall reduction during the second interval is likely to have had the strongest influence on growth rates. Other environmental factors such as temperature, insolation, humidity and fires also may have influenced growth during the first and third intervals, when the rainfall difference was low. For instance, three ground fires occurred in the plot during the first interval (during early 1989, 1991 and 1992) and two fires occurred in the second interval (early 1994 and 1996), while none occurred in the third interval. Fires may influence growth via damage to tissue, reduction of competition (for light and resources) by causing mortalities, destruction of pests at or near ground-level and changes of soil fertility by ash deposition. In addition, the interactions between rainfall and other environmental variables such as temperature, humidity, sunlight, fire, topography, soils and neighbour identity or density, and their combined influences on tree growth require further study. A separate analysis carried out by us (C D Nath, H S Suresh, H S Dattaraja, N V Joshi and R Sukumar, manuscript in review) of the influence of spatial environmental variation have indicated that topographic factors and neighbouring trees also influence growth rates in a few common species; however, this effect appears limited in comparison to that of temporal environmental variations. Thus, we believe that the dominating environmental influences in the Mudumalai dry forest are likely to be rainfall and fire, and our results indicate that deficit rainfall may limit growth in most species of the Mudumalai dry forest.
The association of low rainfall with high growth in small stems of the understory species $C$. fistula during the second interval may be due to widespread mortalities, mainly due to fire and elephants (Sukumar et al 2005), that occurred in the first and second intervals, reducing the population by $33 \%$ and $40 \%$ in the second and third intervals, respectively. This suggests that while rainfall may limit growth of most trees in this dry deciduous forest, light availability also may limit growth for some understorey species, especially in the juvenile classes.

\subsection{Intrinsic factors affecting growth}

In a few common species of Mudumalai growth was related to stem size; however, the relationships were generally weak. This is in contrast to many tropical moist forest studies that found strong positive relationships between tree diameter and growth (Swaine et al 1987; Condit et al 1993b; King et al 2006). The relationship between stem diameter and growth usually has been associated with crown illumination (Clark and Clark 1999; Turner 2001; King et al 2005, 2006). However, in Mudumalai the generally weak, and sometimes negative, diameter-growth relationship indicates that factors other than stem size (and therefore crown position or leafarea/biomass ratios) may have equal or more important influences on growth.

Low growth was generally observed among medium sized saplings (approximately $50-300 \mathrm{~mm} \mathrm{dbh}$ ) that may be due to increased competition. We infer increased competition among stems of these size classes from their generally high frequencies in the plot (table 1). In particular, 100-200 $\mathrm{mm}$ stems constituted the modal frequency class with highest skewness values in all three intervals, lowest average growth rates in the first and third intervals, and highest kurtosis in the third interval (table 1), suggesting that competition affects growth most strongly in these saplings. The largest size classes in some common species appeared most sensitive to environmental stresses in the second interval, supporting earlier findings in other seasonal forests (Pelissier and Pascal 2000; Baker et al 2002).

Species-specific effects on growth were generally stronger than size-specific effects in the Mudumalai dry forest. Several common species had generally high or low growth, although most species' growth rates fluctuated across time intervals due to temporal environmental variation, and also possibly due to developmental plasticity. The consistent differentiation between species growth rates may be important for maintaining diversity in this forest and interactions with time or size classes suggests that certain environmental conditions or size classes may favour greater differentiation between species' growth rates. This requires further investigation. 
Canopy and understory trees did not differentiate into separate groups or along a continuum of growth rates. A large proportion of canopy and understory species occurred together showing no clear canopy-understory growth dichotomy, suggesting that there is flexibility of growth strategies for canopy and understory trees in different size classes and time intervals. However, a few small groups of species may represent strategies similar to those described in rainforests. For example, juveniles of the canopy species $T$. crenulata and A. latifolia may represent a strategy similar to that of slowgrowing shade-tolerant species in wetter forests (Lieberman et al 1985; Nascimento et al 2005), although the same strategy was not evident in the adults. At the other growth extreme, C. fistula, $K$. calycina and $H$. isora adults suggested an "understory species" growth strategy of high relative growth rates. Also, a "canopy species" growth strategy might be generally represented by some or all of the canopy species $L$. microcarpa, D. montana, G. tiliaefolia, S. cumini, S. colais, T. bellirica, B. ceiba, S. oleosa and T. grandis. However, lack of consistency of these groupings across time or size classes, and the general similarity in many canopy and understory species' growth parameters suggest that variable climatic regimes and other disturbances might limit growth guild specialization in the Mudumalai dry forest. Further investigations are required that include recruitment, mortality and other demographic parameters, in order to see if the growth-based groupings detected here constitute demographic guilds.

Perhaps the most important limiting resource gradient for growth in tropical moist and aseasonal forests is light availability, along which species may specialize or differentiate into growth or demographic guilds (Turner 2001; King et al 2005,2006 ), whereas in the relatively open-canopied dry tropical forests trees may not experience similarly high levels of light limitation and, thus, may not show the "gap phase dynamics" commonly described from tropical moist forests (Swaine et al 1990; Sukumar et al 1992). However, an equally or more important resource gradient in the dry forests may be soil water availability, especially during seasonal droughts, and species may specialize or differentiate into guilds based on strategies to deal with seasonal drought stress (Baker et al 2002, 2003b). Hence, future attempts to separate dry tropical forest species into growth guilds might benefit from additional information on phenology, seasonal storage organs (including underground storage) and root growth strategies (Meinzer et al 1999; Enquist and Leffler 2001; Baker et al 2002, 2003a), as well as factors associated with fire tolerance, such as root and stem coppicing, wood density and bark thickness (Gignoux et al 1997; Sukumar et al 2005).

\subsection{Relationship between growth variations and survival}

Relative growth variations during the first two intervals generally did not affect mortality during subsequent years, suggesting that Mudumalai dry forest trees are tolerant of a broad range of growth variations, including stem shrinkage, that may be caused by climatic variations. Unpredictable environments can select for traits that show short-term physiological or functional plasticity during the lifetime of an organism (Schlichting 1986; Sultan 2000), and for plants functional plasticity is important due to their lack of mobility (Bradshaw 1972; Schlichting 1986; Huey et al 2002). Previous studies have demonstrated that root growth, branch growth and biomass allocation can show highly plastic responses to stress, spatial heterogeneity and temporal variability of resources in the environment (Nicotra et al 1997; Sultan et al 1998; Vretare et al 2001). Our results suggest that temporal variation of stem diameters in response to environmental variations such as seasonal drought, as well as its tolerance, can be considered as functionally plastic traits of tropical dry forest species. This may be mediated by seasonal expansion or shrinkage of elastic storage and transport tissues in the stem (Sheil 1995; Baker et al 2002) that may facilitate rapid mobilization of water and nutrients between above- and below-ground organs of the plant

Less commonly, in 100-200 $\mathrm{mm}$ dbh saplings of $L$. microcarpa increased densities may make this size class more vulnerable to unfavourable growth variations so that faster and less variable relative growth rates may be required to survive. Paradoxically, faster growth in medium saplings of $K$. calycina was associated with higher mortality due to elephants. Being one of the fastest growing in the sapling classes, $K$. calycina saplings may have fewer anti-herbivore defences, making them more attractive to elephants.

\subsection{Comparison of Mudumalai seasonally dry forest with other tropical forests}

Previously it has been suggested that tropical dry forests are likely to have lower annual growth rates and net primary productivity than moist forests due to the shorter growing period of the former (Murphy and Lugo 1986). However, the range of growth rates reported for Mudumalai dry forest species appears broadly comparable to those reported for other dry and moist tropical forests around the world. In addition, a comparison of growth rates across four large and two small tropical forest plots around the world (table 4), all of which used standardized protocols for data collection and analysis (Losos and Leigh 2004), revealed that Mudumalai trees clearly had the fastest average growth rates in the smallest size class. It is possible that trees in wetter forests are limited by other factors such as low light or poor soils (Baker et al 2003a, b), resulting in realized annual growth rates that are similar to those of the deciduous water-stressed trees of Mudumalai. On the other hand, Mudumalai dry forest trees experience a short growing interval coupled with severe environmental disturbances in the form of 
Table 4. Comparison of Mudumalai tree growth rates in three different dbh size classes, with those of other plots in the Centre for Tropical Forest Science Forest Dynamics Plots (CTFS FDP) network.

\begin{tabular}{|c|c|c|c|c|c|c|c|c|}
\hline \multirow[b]{3}{*}{ Plot location, Date, Size } & \multirow[b]{3}{*}{$\mathrm{Rf}(\mathrm{mm})$} & \multirow[b]{3}{*}{ Dry Mo. } & \multirow[b]{3}{*}{ Temp $\left({ }^{\circ} \mathrm{C}\right)$} & \multirow[b]{3}{*}{ Vegetation type } & \multirow[b]{3}{*}{ Interval } & \multirow{2}{*}{\multicolumn{3}{|c|}{$\begin{array}{c}\text { Mean growth }\left(\mathrm{mm} \cdot \mathrm{yr}^{-1}\right) \\
\text { Dbh size class }(\mathrm{cm})\end{array}$}} \\
\hline & & & & & & & & \\
\hline & & & & & & $1-9.9$ & $10-29.9$ & $\geq 30$ \\
\hline $\begin{array}{l}\text { Nanjenshan, Taiwan } \\
\text { 1989, } 3 \text { ha. }\end{array}$ & 3582 & 0 & $\begin{array}{l}20.3 \\
26.8\end{array}$ & $\begin{array}{l}\text { Evergreen rainforest } \\
\text { (montane) }\end{array}$ & $1991-97$ & 1.14 & 1.62 & 2.74 \\
\hline $\begin{array}{l}\text { Lambir, Malaysia } \\
\text { 1991, } 52 \text { ha. }\end{array}$ & 2725 & 0 & $\begin{array}{l}22.9 \\
30.3\end{array}$ & $\begin{array}{l}\text { Mature lowland mixed } \\
\text { dipterocarp, evergreen }\end{array}$ & $1992-97$ & 0.52 & 1.63 & 2.7 \\
\hline BCI, Panama & 2551 & $5-6$ & 23.2 & Semideciduous & $1982-85$ & 1.02 & 3.26 & 6.47 \\
\hline \multirow[t]{2}{*}{1980,50 ha. } & & & 31.1 & lowland moist forest & $1985-90$ & 0.82 & 2.32 & 6.07 \\
\hline & & & & & $1990-95$ & 0.58 & 2.14 & 3.88 \\
\hline Bukit Timah, Singapore & 2473 & 0 & 23.1, & Coastal hill forest & $1993-95$ & 0.94 & 2.8 & 4.19 \\
\hline 1993, 2 ha. & & & 30.7 & evergreen/ everwet & $1995-2003$ & 0.5 & 2.35 & 3.79 \\
\hline Pasoh, Malaysia & 1571 & 1 & 22.7 & Lowland mixed & $1986-90$ & 1.36 & 2.33 & 3.37 \\
\hline \multirow[t]{2}{*}{1986,50 ha. } & & & 33.2 & dipterocarp & $1990-95$ & 0.63 & 2.13 & 3.79 \\
\hline & & & & & $1995-2000$ & 0.42 & 1.38 & 2.45 \\
\hline $\begin{array}{l}\text { Huai Kha Khaeng, Thailand } \\
1992,50 \text { ha. }\end{array}$ & 1476 & 6 & $\begin{array}{l}17.7 \\
30.4\end{array}$ & Seasonal dry evergreen & 1993-99 & 1.84 & 2.5 & 3.13 \\
\hline Mudumalai, India, & 1200 & $5-6$ & 17.3, & Dry (and partly moist) & $1988-92$ & 3.69 & 2.77 & 3.74 \\
\hline \multirow[t]{2}{*}{1988,50 ha } & & & 28.2 & deciduous & $1992-96$ & 2.9 & 1.67 & 1.82 \\
\hline & & & & & $1996-2000$ & 3.29 & 2.2 & 3.22 \\
\hline
\end{tabular}

Plots are arranged in order of decreasing mean annual rainfall. Date, Year of initiation; Size, plot size in hectares; Rf., Mean annual rainfall; Dry Mo., number of dry months $\left(<100 \mathrm{~mm}\right.$ rainfall) per year; Temp. $\left({ }^{\circ} \mathrm{C}\right)$, Mean daily minimum and maximum temperature, in degrees Celsius. (All data from Losos and Leigh 2004).

unpredictable and frequent ground fires, and damage by large mammalian herbivores. Also, on account of frequent fires in Mudumalai a large proportion of recruits in the plot $(87 \%$ to $99.8 \%$ annually) were root and stem sprouts, which may rely more on underground storage organs than on light for their relatively fast growth (Sukumar et al 2005). These factors together may have resulted in the extremely fast juvenile growth rates observed indicating that high environmental variability promotes growth plasticity in this forest.

Another difference between Mudumalai growth rates and those of the other plots is that all the other plots showed average growth rates increasing with size class, whereas Mudumalai had highest growth rates in the smallest size class in two out of three time intervals (table 4). Also, the coefficients of variation $(\mathrm{CV})$ of growth rates across size classes per measurement interval was generally lowest for Mudumalai, which reflected the lack of relationship between size and growth rates, compared to the strong positive relationship evident in all the other (generally wetter) sites. Finally, growth rates across multiple census intervals for the smallest stems in Mudumalai generally had the lowest CV and the largest stems had the highest $\mathrm{CV}$, whereas in the other three plots with multiple censuses growth rates of the smallest stems had the highest CV while the largest stems had relatively low CV. This supports our earlier conclusion that environmental factors in Mudumalai may have selected for species with invariably fast growth in small stems.

The substantial variation in growth rates across different time intervals highlights the need for long term monitoring of tropical forests (Hubbell and Foster 1992; Clark and Clark 1999; Losos and Leigh 2004). Our current results suggest that in order to understand and predict vegetation dynamics in the dry tropics, local monitoring of short and long term climatic variations may be of equal importance.

\section{Acknowledgements}

Funding from Ministry of Environment and Forests, New Delhi, has supported fieldwork in the Mudumalai Forest Dynamics Plot. We thank Forest Department of Tamilnadu for research permissions, and Mr Narasimhan and Mr Javaraiah (Tamilnadu Electricity Board) for providing rainfall data for Gamehut. Analyses were aided by an analytical workshop (in which CDN, HSD, and HSS participated) run by Center for Tropical Forest Science, Smithsonian Tropical Research Institute (NSF grant \#0090311). We thank C M Bharanaiah, R Arumugam, Shivaji, Sidda, Annadurai, M Bomman and 
other CES staff for help with collecting data. Comments and suggestions by Prof. Christopher Wills, Soumya Prasad and two anonymous reviewers improved the manuscript.

\section{Appendix 1}

Details of three different methods used to fill gaps in the daily rainfall data of Kargudi weather station, located three $\mathrm{km}$ south of the plot, using semi-monthly data available from Gamehut weather station, located four km west of the plot. Gamehut data were first converted to daily values and the missing Kargudi data were then estimated with the help of predictive equations between Kargudi (the dependent variable, $y$, in all equations below) and Gamehut daily values (the independent variable, $x$, in all equations below). Numbers given below, per season or month, represent parameter values for the predictive linear and non-linear equations used.

Method 1: 'Annual' method used a common linear equation, $y=a+\left(b^{*} x\right)$, to fill all gaps in Kargudi data between 1988 and 2000 .

Intercept $(a)=1.09$, slope $(b)=0.978$.

Method 2: 'Seasonal' method used separate linear equations, $y=a+\left(b^{*} x\right)$, per season:

Cool dry season (January-March): 1.333, 1.948.

Hot dry season (April-May): 6.491, 0.973.
Monsoon1 season (June-September): 5.542, 0.974.

Monsoon2 season (October-December): -7.431, 1.080.

Method 3: 'Monthly' method used a different linear or nonlinear equation per month (months 1-12 are in order from January to December), as follows:

Months 1 to 5: Linear regression, $y=a+\left(b^{*} x\right)$.

Month 1: 0.715, -0.409 .

Month 2: 0.204, 0.643 .

Month 3: 1.463, 3.088.

Month 4: 4.273, 1.138 .

Month 5: 1.853, 0.939 .

Months 6, 7, 11 and 12: Quadratic regression, $y=a+$ $(b * x)+(c * x * x)$.

Month 6: 18.734, 0.526, 0.003.

Month 7: 6.288, 0.866, 0.001.

Month 11: 0.061, 0.768, 0.002.

Month 12: 0.360, 0.277, 0.013.

Month 8: Exponential association, $y=a^{*}\left(1-\exp \left(-b^{*} x\right)\right)$

Month 8: 206.442, 0.009.

Months 9 and 10: Logistic equation, $y=a /\left(1+\left(b^{*} \exp \right.\right.$ $\left.\left(-c^{*} x\right)\right)$ ).

Month 9: 106.429, 12.752, 0.051.

Month 10: 327.217, 42.485, 0.024.

The top ten best-fitting curves for each month were obtained using CurveExpert (trial ver. 1.34) and final curve selection was based on the variance explained, number of parameters and curve shape.

\section{Appendix 2.}

Scientific names of tree species in the Mudumalai 50 ha plot corresponding to the codes used in tables and figures, along with growth form and family classifications. Nomenclature follows Gamble (1935), as updated by Mabberley (2005).

\begin{tabular}{llllll}
\hline Code & Scientific name & Family & Code & Scientific name & Family \\
\hline \multicolumn{2}{c}{ CANOPY SPECIES } & & & & \multicolumn{2}{c}{ UNDERSTORY SPECIES } \\
albo & Albizia odoratissima & Leguminosae & baur & Bauhinia racemosa & Leguminosae \\
anol & Anogeissus latifolia & Combretaceae & butm & Butea monosperma & Leguminosae \\
artg & Artocarpus gomezianus & Moraceae & cand & Canthium dicoccum & Rubiaceae \\
baum & Bauhinia malabarica & Leguminosae & cara & Careya arborea & Lecythidaceae \\
bisj & Bischofia javanica & Euphorbiaceae & casf & Cassia fistula & Leguminosae \\
bomm & Bombax ceiba & Bombacaceae & corw & Cordia wallichii & Boraginaceae \\
brir & Bridelia retusa & Euphorbiaceae & daln & Dalbergia lanceolaria & Leguminosae \\
case & Casearia esculenta & Flacourtiaceae & eriq & Eriolaena quinquelocularis & Sterculiaceae \\
chut & Chukrasia tabularis & Meliaceae & flai & Flacourtia indica & Flacourtiaceae \\
coro & Cordia obliqua & Boraginaceae & kydc & Kydia calycina & Malvaceae \\
dall & Dalbergia latifolia & Leguminosae & phye & Phyllanthus emblica & Euphorbiaceae \\
diom & Diospyros montana & Ebenaceae & rand & Catunaregam spinosa & Rubiaceae \\
elag & Cassine glauca & Celastraceae & vita & Vitex altissima & Labiatae
\end{tabular}




\begin{tabular}{|c|c|c|c|c|c|}
\hline eryi & Erythrina variegata & Leguminosae & writ & Wrightia tinctoria & Apocynaceae \\
\hline garp & Garuga pinnata & Burseraceae & zizr & Ziziphus rugosa & Rhamnaceae \\
\hline gmea & Gmelina arborea & Labiatae & zizx & Ziziphus xylopyrus & Rhamnaceae \\
\hline gret & Grewia tiliaefolia & Tiliaceae & & & \\
\hline hymo & Hymenodictyon orixense & Rubiaceae & & & \\
\hline lagl & Lagerstroemia microcarpa & Lythraceae & & & \\
\hline lagp & Lagerstroemia parviflora & Lythraceae & \multicolumn{3}{|c|}{$\underline{\text { SHRUB SPECIES }}$} \\
\hline lanc & Lannea coromandelica & Anacardiaceae & allc & Allophylus cobbe & Sapindaceae \\
\hline madn & Madhuca nilifolia & Sapotaceae & antd & Antidesma diandrum & Euphorbiaceae \\
\hline mani & Mangifera indica & Anacardiaceae & greh & Grewia hirsuta & Tiliaceae \\
\hline mitp & Mitragyna parvifolia & Rubiaceae & heli & Helicteres isora & Sterculiaceae \\
\hline oled & Olea dioica & Oleaceae & inde & Indigofera cassioides & Leguminosae \\
\hline ougo & Desmodium oojeinense & Leguminosae & malp & Mallotus philippensis & Euphorbiaceae \\
\hline pret & Premna tomentosa & Labiatae & & & \\
\hline ptem & Pterocarpus marsupium & Leguminosae & & & \\
\hline scho & Schleichera oleosa & Sapindaceae & & & \\
\hline schs & Schrebera swietenioides & Oleaceae & & & \\
\hline sema & Semecarpus anacardium & Anacardiaceae & & & \\
\hline shor & Shorea roxburghii & Dipterocarpaceae & & & \\
\hline step & Stereospermum colais & Bignoniaceae & & & \\
\hline stet & Radermachera xylocarpa & Bignoniaceae & & & \\
\hline syzc & Syzygium cumini & Myrtaceae & & & \\
\hline tecg & Tectona grandis & Labiatae & & & \\
\hline terb & Terminalia bellirica & Combretaceae & & & \\
\hline terc & Terminalia chebula & Combretaceae & & & \\
\hline tert & Terminalia crenulata & Combretaceae & & & \\
\hline
\end{tabular}

\section{References}

Baker T R, Afflum-Baffoe K, Burslem D F R P and Swaine M D 2002 Phenological differences in tree water use and the timing of tropical forest inventories: Conclusions from patterns of dry season diameter change; For. Ecol. Manage. 171 261-274

Baker T R, Burslem D F R P and Swaine M D 2003a Associations between tree growth, soil fertility and water availability at local and regional scales in Ghanaian tropical rain forest; J. Trop. Ecol. 19 109-125

Baker T R, Swaine M D and Burslem D F R P 2003b Variation in tropical forest growth rates: combined effects of functional group composition and resource availability; Persp. Pl. Ecol. Evol. Syst. 6 21-36

Bradshaw A D 1972 Some of the evolutionary consequences of being a plant; Evol. Biol. 5 25-47

Breitsprecher A and Bethel J S 1990 Stem-growth periodicity of trees in a tropical wet forest of Costa Rica; Ecology 71 1156-1164
Clark D A and Clark D B 1992 Life history diversity of canopy and emergent trees in a neotropical rain forest; Ecol. Monogr. 62 315-344

Clark D A and Clark D B 1994 Climate-induced annual variation in canopy tree growth in a Costa Rican tropical rain forest; $J$. Ecol. 82 865-872

Clark D A and Clark D B 1999 Assessing the growth of tropical rain forest trees: issues for forest modeling and management; Ecol. Appl. 9 981-997

Condit R, Hubbell S P and Foster R B 1993a Mortality and growth of a commercial hardwood 'el cativo', Prioria copaifera, in Panama; For. Ecol. Manage. 62 107-122

Condit R, Hubbell S P and Foster R B 1993b Identifying fastgrowing native trees from the Neotropics using data from a large, permanent census plot; For. Ecol. Manage. 62 123-143

Condit R, Hubbell S P and Foster R B 1996 Assessing the response of plant functional types to climatic change in tropical forests; J. Veg. Sci. $7405-416$

Condit R, Aguilar S, Hernandez A, Perez R, Lao S, Angehr G, Hubbell S P and Foster R B 2004 Tropical forest dynamics 
across a rainfall gradient and the impact of an El Nino dry season; J. Trop. Ecol. 20 51-72

Daubenmire R 1972 Phenology and other characteristics of tropical semi-deciduous forest in north-western Costa Rica; J. Ecol. 60 $147-170$

Dobbertin M 2005 Tree growth as indicator of tree vitality and of tree reaction to environmental stress: a review; Eur. J. For. Res. 124 319-333

Enquist B J and Leffler A J 2001 Long-term tree ring chronologies from sympatric tropical dry-forest trees: individualistic responses to climatic variation; J. Trop. Ecol. 17 41-60

Gamble J S 1935 Flora of the Presidency of Madras (London: Adlard)

Gentry A H 1995 Diversity and floristic composition of neotropical dry forests; in Seasonally dry tropical forests (eds) S H Bullock, H A Mooney and E Medina (Cambridge: Cambridge University Press) pp 146-194

Gerhardt K and Hytteborn H 1992 Natural dynamics and regeneration methods in tropical dry forests: an introduction; J. Veg. Sci. 3 361-364

Gignoux J, Clobert J and Menaut J-C 1997 Alternative fire resistance strategies in savanna trees; Oecologia 110 576-583

Harper J L 1977 Population biology of plants (London: Academic Press)

Hubbell S P and Foster R B 1992 Short-term dynamics of a neotropical forest: Why ecological research matters to tropical conservation and management; Oikos 63 48-61

Huey R B, Carlson M, Crozier L, Frazier M, Hamilton H, Harley C, Hoang A and Kingsolver J G 2002 Plants Versus Animals: Do They Deal with Stress in Different Ways?; Integ. Compar. Biol. 42 415-423

King D A, Davies S J, Supardi M N N and Tan S 2005 Tree growth is related to light interception and wood density in two mixed dipterocarp forests of Malaysia; Func. Ecol. 19 445-453

King D A, Davies S J and Noor N S M 2006 Growth and mortality are related to adult tree size in a Malaysian mixed dipterocarp forest; For. Ecol. Manage. 223 152-158

Lang G E and Knight D H 1983 Tree growth, mortality, recruitment, and canopy gap formation during a 10 -year period in a tropical moist forest; Ecology 64 1075-1080

Lieberman D, Lieberman M, Hartshorn G and Peralta R 1985 Growth rates and age-size relationships of tropical wet forest trees in Costa Rica; J. Trop. Ecol. 1 97-109

Lieberman D and Lieberman M 1987 Forest tree growth and dynamics at La Selva, Costa Rica (1969-1982); J. Trop. Ecol. $3347-358$

Losos E C and Leigh E G Jr 2004 Tropical forest diversity and dynamism: Findings from a large-scale plot network (Chicago: University of Chicago Press)

Ludwig J A and Reynolds J F 1988 Statistical ecology: A primer on methods and computing (New York: John Wiley)

Mabberley D J 2005 The plant-book: A portable dictionary of the vascular plants (Cambridge: Cambridge University Press)

Manokaran N, Quah E S, Ashton P S, Lafrankie J V, Nur Supardi M N, Wan Mohd Shukri W A and Okuda T 2004 Pasoh forest dynamics plot, peninsular malaysia; in Tropical forest diversity and dynamism: Findings from a large-scale plot network (eds)
E C Losos and E G Leigh Jr (Chicago: University of Chicago Press) pp 585-598

Meinzer F C, Andrade J L, Goldstein G, Holbrook N M, Cavelier J and Wright S J 1999 Partitioning of soil water among canopy trees in a seasonally dry forest; Oecologia $\mathbf{1 2 1}$ 293-301

Murphy P G and Lugo A E 1986 Ecology of tropical dry forest; Annu. Rev. Ecol. Syst. 17 67-88

Nascimento H E M, Laurance W F, Condit R, Laurance G S, D'Angelo S and Andrade A 2005 Demographic and life-history correlates for Amazonian trees; J. Veg. Sci. 16 625-634

Nicotra A B, Chazdon R L and Schlichting C D 1997 Patterns of genotypic variation and phenotypic plasticity of light response in two tropical Piper (Piperaceae) Species; Am. J. Bot. 84 $1542-1552$

Pelissier R and Pascal J-P 2000 Two-year tree growth patterns investigated from monthly growth records using dendrometer bands in a wet evergreen forest in India; J. Trop. Ecol. 16 429-446

Primack R B, Ashton P S, Chai P and Lee H S 1985 Growth rates and population structure of Moraceae trees in Sarawak, East Malaysia; Ecology 66 577-588

Reich P B and Borchert R 1984 Water stress and tree phenology in a tropical dry forest in the lowlands of Costa Rica; J. Ecol. 72 61-74

Schlichting C D 1986 The evolution of phenotypic plasticity in plants; Annu. Rev. Ecol. Syst. 17 667-693

Sheil D 1995 A critique of permanent plot methods and analysis with examples from Budongo Forest, Uganda; For. Ecol. Manage. 77 11-34

Sokal R, R. and Rohlf F J 1998 Biometry: The principles and practice of statistics in biological research (New York: W H Freeman)

Sukumar R, Dattaraja H S, Suresh H S, Radhakrishnan J, Vasudeva R, Nirmala S and Joshi N V 1992 Long-term monitoring of vegetation in a tropical deciduous forest in Mudumalai, southern India; Curr. Sci. 62 608-616

Sukumar R, Suresh H S, Dattaraja H S, John R and Joshi N V 2004 Mudumalai forest dynamics plot, India; in Tropical forest diversity and dynamism: Findings from a large-scale plot network (eds) E C Losos and E G Leigh Jr (Chicago: University of Chicago Press) pp 551-563

Sukumar R, Suresh H S, Dattaraja H S, Srinidhi S and Nath C 2005 The dynamics of a tropical dry forest in India: Climate, fire, elephants and the evolution of life-history strategies; in Biotic interactions in the tropics: Their role in the maintenance of species diversity (eds) D Burslem, M Pinard and S Hartley (Cambridge: Cambridge University Press) pp 510-529

Sultan S E, Wilczek A M, Bell D L and Hand G 1998 Physiological response to complex environments in annual Polygonum species of contrasting ecological breadth; Oecologia 115 564-578

Sultan S E 2000 Phenotypic plasticity for plant development, function and life history; Trends Pl. Sci. 5 537-542

Swaine M D, Hall J B and Alexander I J 1987 Tree population dyna-mics at Kade, Ghana (1968-1982); J. Trop. Ecol. 3 $331-345$ 
Swaine M D, Lieberman D and Hall J B 1990 Structure and dynamics of a tropical dry forest in Ghana; Vegetatio 88 31-51

Turner I M 2001 The ecology of trees in the tropical rain forest (Cambridge: Cambridge University Press)

Vretare V, Weisner S E B, Strand J A and Granéli W 2001 Phenotypic plasticity in Phragmites australis as a functional response to water depth; Aq. Bot. 69 127-145
Welden C W, Hewett S W, Hubbell S P and Foster R B 1991 Sapling survival, growth, and recruitment: relationship to canopy height in a neotropical forest; Ecology $\mathbf{7 2}$ 35-50

Wright S J, Carrasco C, Calderon O and Paton S 1999 The El Nino southern oscillation, variable fruit production, and famine in a tropical forest; Ecology 80 1632-1647

MS received 17 April 2006; accepted 14 October 2006

ePublication: 13 November 2006

Corresponding editor: R GEETA 